\title{
Some locally convex spaces of regular distributions
}

by

PETER DIEROLF (Trior)

Dedicated to Professor Jan Mikusinski

on the occasion on this Yoth birthday.

Abstract. We investigate two spaces of locally integrable functions which are defined by the way their eloments generate tempered distributions on $\boldsymbol{R}^{n}$. We first. give characterizations of these spaces and then investigate the locally convex topologies which are suggested by the structure of these spacos. A detailed description of the topologieal properties of these LB-spaces and LF-spaces is obtained.

Introduction and synopsis. A distribution $T \in \mathscr{D}\left(\boldsymbol{R}^{n}\right)^{\prime}$ is called regular. if there exists $f \in I_{100}^{1}\left(\boldsymbol{R}^{n}\right)$ such that

$$
\langle T, \varphi\rangle=\int_{\boldsymbol{R}^{n}} f(x) \varphi(x) d x \quad\left(\varphi \in \mathscr{D}\left(\boldsymbol{R}^{n}\right)\right)
$$

holds (cf. e.g. Gel'fand, Shilov [13], p. 82). If instead of $\mathscr{D}\left(\boldsymbol{R}^{n}\right)$ we consider a space $H$ of testfunctions which is not a subspace of $L_{c}^{\infty}\left(\boldsymbol{R}^{n}\right)$ (= essentially bounded functions with compact support), it is no longer evident how elements of the dual $H^{\prime}$ may be represented by locally integrable functions. However, the question is important since the calculation of fundamental solutions to partial differential operators often yields locally integrable functions or limits of such functions (cf. (1..5) below).

In this paper we investigate this question for the space $H:=\mathscr{P}\left(\boldsymbol{R}^{n}\right)$, the space of testfunctions for tempered distributions on $\boldsymbol{R}^{n}$. There exist. two natural possibilities to represent tempered distributions by locally integrable functions:

(I) We may consider only those functions $f \in L_{\text {loo }}^{1}\left(\boldsymbol{R}^{n}\right)$ which satisfy $f \cdot \varphi \in L^{1}\left(\boldsymbol{R}^{n}\right)$ for all $\varphi \in \mathscr{S}\left(\boldsymbol{R}^{n}\right)$. For such functions $f$ the linear form

$$
\varphi \mapsto \int_{\boldsymbol{R}^{n}} f(x) \varphi(x) d x
$$


is continuous on $\mathscr{P}\left(\boldsymbol{R}^{n}\right)$. This leads to the definition of the space

$$
S_{\mathrm{ar}}\left(\boldsymbol{R}^{n}\right):=\left\{f \in L_{\mathrm{loc}}^{\mathrm{I}}\left(\boldsymbol{R}^{n}\right) ; f \cdot \varphi \in L^{1}\left(\boldsymbol{R}^{n}\right) \forall \varphi \in \mathscr{P}\left(\boldsymbol{R}^{n}\right)\right\}
$$

.of absolutely regular tempered distributions. form

(II) We may consider all functions $f \in L_{\text {loc }}^{1}\left(\boldsymbol{R}^{n}\right)$ for which the linear

$$
\varphi \mapsto \int_{\boldsymbol{R}^{n}} f(x) \varphi(x) d x \quad\left(\varphi \in \mathscr{D}\left(\boldsymbol{R}^{n}\right)\right)
$$

on $\mathscr{D}\left(\boldsymbol{R}^{n}\right)$ is continuous with respect to the topology induced by $\mathscr{P}\left(\boldsymbol{R}^{n}\right)$ on $\mathscr{D}\left(\boldsymbol{R}^{n}\right)$. This leads to the definition of the space

$$
S_{\mathrm{r}}\left(\boldsymbol{R}^{n}\right):=\mathscr{S}\left(\boldsymbol{R}^{n}\right)^{\prime} \cap L_{100}^{1}\left(\boldsymbol{R}^{n}\right)
$$

of regular tempered distributions. (For the above intersection both spaces $\mathscr{P}\left(\boldsymbol{R}^{n}\right)^{\prime}$ and $L_{\text {loc }}^{1}\left(\boldsymbol{R}^{n}\right)$ are considered in the natural way as subspaces of $\left.\mathscr{D}\left(\boldsymbol{R}^{n}\right)^{\prime}.\right)$ For $f \in S_{\mathrm{r}}\left(\boldsymbol{R}^{n}\right)$ and $\varphi \in \mathscr{S}\left(\boldsymbol{R}^{n}\right)$ the value $\langle f, \varphi\rangle$ has to be calculated by an approximation procedure.

In Sections 1 and 2 we characterize the spaces $S_{\mathrm{ar}}\left(\boldsymbol{R}^{n}\right)$ and $\boldsymbol{S}_{\mathrm{r}}\left(\boldsymbol{R}^{n}\right)$, respectively. We also prove several results concerning the structure of these spaces. Our main concern is then the investigation of locally convex topologies on the spaces $S_{\text {ar }}\left(\boldsymbol{R}^{n}\right)$ and $S_{x}\left(\boldsymbol{R}^{n}\right)$ which are suggested by the structure of these spaces. This investigation is presented in Sections 3 and 4. It turns out that these spaces may be provided in a natural way with an LB-space topology $\mathfrak{I}$ and an LF-space topology $\mathfrak{F}$, respectively. In the proof of the topological properties of $\left(\boldsymbol{S}_{\mathrm{ar}}\left(\boldsymbol{R}^{n}\right), \mathfrak{I}\right)$ we strongly use the fact that $S_{a r}\left(\boldsymbol{R}^{n}\right)$ is a Köthe-function space in the sense of Dieudonné [10]. Thanks to this fact we are in the especially nice situation to have an inductive representation, as well as a projective representation, for $\mathfrak{I}$. The proof of the topological properties of $\left(S_{\mathrm{r}}\left(\boldsymbol{R}^{n}\right), \mathfrak{F}\right)$ uses the representation of $\left(\mathscr{S}\left(\boldsymbol{R}^{n}\right)^{\prime} \beta\left(\mathscr{S}^{\prime}, \mathscr{S}\right)\right)$ as an inductive limit of a sequence of Hilbert-spaces, and the concept of a generalized inductive limit top- ology which was introduced by Garling [12]. By this combination of different methods we obtain a detailed description of the topological properties of the spaces $\left(\mathbb{S}_{\mathrm{ar}}\left(\boldsymbol{R}^{n}\right), \mathfrak{I}\right)$ and $\left(\mathcal{S}_{\mathrm{r}}\left(\boldsymbol{R}^{n}\right), \mathfrak{F}\right)$, respectively.

In Section 5 we describe several interesting phenomenons which occur if we take the space $\mathscr{O}(\Omega)$ as a space of test functions. Some of these phenomenons are due to the fact that this space, in contrast to $\mathscr{P}\left(\boldsymbol{R}^{n}\right)$, is i.g. not reflexive. However, we don't give detailed proofs in this section.

Now we insert a few comments on our notation. We mainly use tho standard notation of Horvath [19] and Schwartz [26], [27]. $\hat{x}^{a}$ denotes the function $x \mapsto x^{a}$, etc. For a locally convex space $(\mathbb{X}, \mathfrak{I})$ we denote the zeronbhd.-filter by $\mathfrak{U}_{0}(E, \mathfrak{T})$. By $L^{0}\left(\boldsymbol{R}^{n}\right)$ we denote the space of (equivalence classes of) Lebesgue-measurable functions. All derivatives are taken in the distributional sense. For $f \in L_{\text {loo }}^{1}\left(\boldsymbol{R}^{n}\right)$ the support of $f$ is the support of $f$ as a distribution on $\boldsymbol{R}^{n}$ (Horváth [19], p. 318).

This article is based on parts of the thesis [6]. I am grateful to my wife Dr. S. Dierolf and to Dr. J. Voigt for several helpful discussions on the subject of this paper.

1. Absolutely regular tempered distributions. We define $\omega_{s}(x):=$ $\left(1+|x|^{2}\right)^{s} \quad\left(x \in \boldsymbol{R}^{n}, s \in \boldsymbol{R}\right)$ and put

$$
\begin{aligned}
& L^{p}\left(\boldsymbol{R}^{n}, \omega_{s}\right):=\left\{f \in I^{0}\left(\boldsymbol{R}^{n}\right) ; \int_{\boldsymbol{R}^{n}}\left(|f(x)| \cdot \omega_{s}(x)\right)^{p} d x<\infty\right\}, \\
& \|f\|_{p, s}:=\left\|f \cdot \omega_{s}\right\|_{p} \quad\left(f \in L^{p}\left(\boldsymbol{R}^{n}, \omega_{s}\right), p \in[1, \infty), s \in \boldsymbol{R}\right) .
\end{aligned}
$$

The space $\left(L^{\infty}\left(\boldsymbol{R}^{n}, \omega_{s}\right),\|\cdot\|_{\infty, s}\right)$ is defined analogously.

As a fundamental system of norms for the standard topology $\mathfrak{s}$ on $\mathscr{S}\left(\boldsymbol{R}^{n}\right)$ we take

$$
q_{k}(p):=\max \left\{\left\|\omega_{k} \cdot \partial^{\alpha} \varphi\right\|_{\infty} ;|\alpha| \leqslant k\right\} \quad\left(\varphi \in \mathscr{S}\left(\boldsymbol{R}^{n}\right), k \in \boldsymbol{N}_{0}\right) .
$$

A sequence $\left(\eta_{k} ; k \in \boldsymbol{N}\right)$ in $\mathscr{D}\left(\boldsymbol{R}^{n}\right)$ wil be called an approximate unit (in $\mathscr{P}\left(\boldsymbol{R}^{n}\right)$ ) if the following conditions are satisfied:

(AP.1) $\lim _{k \rightarrow \infty} \eta_{k}=1$ in $\mathscr{\&}\left(\boldsymbol{R}^{n}\right)$.

(AP.2) $\left\{\eta_{k} ; \eta_{\in} \boldsymbol{N}\right\}$ is bounded in $\mathscr{B}\left(\boldsymbol{R}^{n}\right)$, i.e.,

$$
\forall \alpha \in \boldsymbol{N}_{0}^{n} \exists C_{\alpha}>0 \quad \forall x \in \boldsymbol{R}^{n}, \hbar \in \boldsymbol{N}:\left|\partial^{\alpha} \eta_{k}(x)\right| \leqslant C_{\alpha} .
$$

An easy calculation shows $\lim _{t \rightarrow \infty} \eta_{k} \varphi=\varphi$ in $\left(\mathscr{P}\left(\boldsymbol{R}^{n}\right), \mathfrak{S}\right)$ for all $\varphi \in \mathscr{P}\left(\boldsymbol{R}^{n}\right)$.

(1.1) Proposrmon. For $f \in L_{100}^{1}\left(\boldsymbol{R}^{n}\right)$ the following statements are equivatent:

(a) For every $h \in \mathcal{L}^{\infty}\left(\boldsymbol{R}^{n}\right)$ the linear form

$$
\varphi \mapsto \int_{\boldsymbol{R}^{n}} h(x) f(x) \varphi(x) d x \quad\left(\varphi \in \mathscr{D}\left(\boldsymbol{R}^{n}\right)\right)
$$

is continuous on $\left(\mathscr{D}\left(\boldsymbol{R}^{n}\right), \mathfrak{S} \cap \mathscr{D}\left(\boldsymbol{R}^{n}\right)\right)$.

(b) There exists $m \in \boldsymbol{N}_{0}$ such that $\omega_{-m} \cdot f \in L^{1}\left(\boldsymbol{R}^{n}\right)$.

(c) $f \cdot \varphi \in L^{\lambda}\left(\boldsymbol{R}^{n}\right)$ for all $\varphi \in \mathscr{P}\left(\boldsymbol{R}^{n}\right)$. form

If one of these oonditions is satisfied, for every $h \in L^{\infty}\left(\boldsymbol{R}^{n}\right)$ the linear

$$
\varphi \mapsto \int_{\mathbf{R}^{n}} h(x) \cdot f(x) \cdot \varphi(x) d x
$$

is continuous on $\left(\mathscr{S}\left(\boldsymbol{R}^{n}\right), \mathcal{S}\right)$. 
Proof. $(\mathrm{a}) \Rightarrow(\mathrm{b})$ : By (a) there exists $m \in \boldsymbol{N}_{0}$ and $C>0$ such that

$$
\left|\int_{\boldsymbol{R}^{n}}\right| f(x)|\varphi(x) d x| \leqslant C \cdot q_{n}(\varphi) \quad\left(\varphi \in \mathscr{D}\left(\boldsymbol{R}^{n}\right)\right)
$$

holds. Let $\eta \in \mathscr{D}\left(\boldsymbol{R}^{n}\right)$ satisfy $\eta \geqslant 0$ and $\eta(x)=1$ near $0 \in \boldsymbol{R}^{n}$. Then the sequence defined by $\eta_{k}(x):=\eta(x / k) \quad\left(x \in \boldsymbol{R}^{n}, k \in \boldsymbol{N}\right)$ satisfies (AP.1) and (AP.2) from above. Using the formula for the derivatives of composite functions (cf. Fraenkel [11], p. 163, or [6], \$15) wo obtain the existence of constants $C(-m, \beta)>0\left(\beta \in \boldsymbol{N}_{0}^{n}\right)$ such that

$$
\left|\partial^{\beta} \omega_{-m}(x)\right| \leqslant C(-m, \beta) \cdot \omega_{-m-|\beta| / 2}(x) \quad\left(x \in \boldsymbol{R}^{n}, \beta \in \boldsymbol{N}_{0}^{n}\right)
$$

holds. By Leibniz' formula and (AP.2) it follows that $\sup \left\{q_{m}\left(\omega_{-m} \cdot \eta_{k}\right)\right.$; $\hbar \in \boldsymbol{N}\}<\infty$. Thus there exists $M>0$ such that

$$
\int_{\boldsymbol{R}^{n}}|f(x)| \omega_{-m}(x) \cdot \eta_{k}(x) d x \leqslant M \quad(k \in \mathbf{N})
$$

holds. Now Fatou's lemma implies (b).

(b) $\Rightarrow(c)$ is obvious.

(c) $\Rightarrow$ (a): By (c) we have $h \cdot f \cdot p \in L^{1}\left(\boldsymbol{R}^{n}\right)$ for all $h \in L^{\infty}\left(\boldsymbol{R}^{n}\right), p \in \mathscr{S}\left(\boldsymbol{R}^{n}\right)$. It is easy to see that the mapping $[h \cdot f]:\left(\mathscr{S}\left(\boldsymbol{R}^{n}\right), \mathfrak{S}\right) \rightarrow\left(L^{1}\left(\boldsymbol{R}^{n}\right),\|\cdot\|_{1}\right)$, $[h \cdot f](\varphi):=h \cdot f \cdot \varphi\left(\varphi \in \mathscr{S}\left(\boldsymbol{R}^{n}\right)\right)$ has closed graph and is thus continuous. This proves (a) and the continuity property at the end of (1.1).

(1.2) Definimion. A tempered distribution $T \in \mathscr{S}\left(\boldsymbol{R}^{n}\right)^{\prime}$ is called absolutely regular if there exists $f \in L_{\text {loc }}^{1}\left(\boldsymbol{R}^{n}\right)$ satisfying the conditions of (1.1) such that

$$
\langle T, \varphi\rangle=\int_{\boldsymbol{R}^{n}} f(x) \varphi(x) d x \quad\left(\varphi \in \mathscr{S}\left(\boldsymbol{R}^{n}\right)\right)
$$

holds. We put

$$
S_{\mathrm{ar}}\left(\boldsymbol{R}^{n}\right):=\left\{f \in I_{\mathrm{loc}}^{1}\left(\boldsymbol{R}^{n}\right) ; f \cdot \varphi \in L^{1}\left(\boldsymbol{R}^{n}\right) \forall \varphi \in \mathscr{P}\left(\boldsymbol{R}^{n}\right)\right\}=\bigcup_{m \in N_{0}} L^{1}\left(\boldsymbol{R}^{n}, \omega_{-m}\right) .
$$

(1.3) Remarks. (a) By first inspection, the statement (1.1a) may seem to be artificial. It is however this statement which should be used to define absolutely regular distributions for other spaces of testiunctions which not necesarily allow the application of a closed graph theorem. The difference between (1.1a) and (1.1c) as a defining statement for absolutely regular distributions becomes evident if we consider $H:=\left(\mathscr{S}\left(\boldsymbol{R}^{n}\right)\right.$, $\|\cdot\|_{1}$ ) as a space of testfunctions.

(b) The proof of $(1.1 \mathrm{a}) \Rightarrow(1.1 \mathrm{~b})$ is due to Schwartz [27], p. 242, Thm. VII; there he characterizes the tempered measures on $\boldsymbol{R}^{n}$.

(c) The notion "absolutely regular" was chosen to resemble the property $f \in S_{\mathrm{ar}}\left(\boldsymbol{R}^{n}\right) \Rightarrow|f| \in \mathcal{S}_{\mathrm{ar}}\left(\boldsymbol{R}^{n}\right)$. (d) We note the following property of $S_{\text {ar }}\left(\boldsymbol{R}^{n}\right)$ :

If $f \in S_{\text {ar }}\left(\boldsymbol{R}^{n}\right), g \in L_{100}^{1}\left(\boldsymbol{R}^{n}\right),|g(x)| \leqslant|f(x)|$ almost everywhere on $\boldsymbol{R}^{n}$, then $g \in S_{a r}\left(\boldsymbol{R}^{n}\right)$, i.e., $S_{\mathrm{ar}}\left(\boldsymbol{R}^{n}\right)$ is a normal subspace of $L_{\mathrm{loc}}^{\mathrm{l}}\left(\boldsymbol{R}^{n}\right)$ in the sense of Dieudonné [10], p. 1.01, 11 .

(e) As was observed by Szmydt [29], p. 310, the characterization of $S_{\mathrm{ar}}\left(\boldsymbol{R}^{n}\right)$ indicated by Gel'fand, Shilov [13], pp. 82, 83, is not correct.

(f) $S_{\text {ar }}\left(\boldsymbol{R}^{n}\right)$ has no stability property with respect to differentiation, as the following example shows.

(1.4) Example. Let $f: \boldsymbol{R} \rightarrow \boldsymbol{C}$ be defined by $f(x):=\exp \left(i \cdot e^{x}\right)(x \in \boldsymbol{R})$. Since $|f(x)|=1(x \in \boldsymbol{R})$, we obtain $f \in S_{\text {ar }}(\boldsymbol{R})$. We have $f \in \mathscr{E}(\boldsymbol{R})$ and $f^{\prime}(x)$ $=i \cdot e^{x} \cdot \exp \left(i \cdot e^{x}\right),\left|f^{\prime}(x)\right|=e^{x}(x \in \boldsymbol{R})$. This implies $f^{\prime} \notin S_{a r}(\boldsymbol{R})$. Nevertheless the function $f^{\prime}$ generates a tempered distribution. We thus have an example of a tempered distribution which (in a sense to be made precise) is "represented" by a locally integrable function $f^{\prime} \notin S_{a r}(\boldsymbol{R})$. This motivates the introduction of regular tempered distributions in the next section.

(1.5) As was already mentioned in the introduction, one of the motives for studying the space $S_{\text {ar }}\left(\boldsymbol{R}^{n}\right)$ is provided by the calculation of fundamental solutions to partial differential operators. Let $P(\partial)=\sum_{|\alpha| \leqslant m} a_{\alpha} \partial^{\alpha}$ be a differential operator with constant coefficients such that the polynomial $x \mapsto P(2 \pi i x)$ has no zeroes on $\boldsymbol{R}^{n}$. Then it follows from Lemma 2 of Hörmander [17], p. 557, that there exist $O>0$ and $k \in \boldsymbol{N}_{0}$ such that

$$
|P(2 \pi i x)|^{-1} \leqslant \theta \cdot\left(1+|x|^{2}\right)^{k} \quad\left(x \in \boldsymbol{R}^{n}\right)
$$

holds. Thus $(P(2 \pi i \hat{x}))^{-1} \in S_{\mathrm{ar}}\left(\boldsymbol{R}^{n}\right)$ and $\mathscr{F}^{-1}\left((P(2 \pi i \hat{x}))^{-1}\right)$ is a tempered fundamental solution to $P(\partial)$. By a skilful "perturbation" of the coefficients one may use this method even for some differential operators $P(\partial)$ for which the polynomial $P(2 \pi i \hat{x})$ has zeroes on $\boldsymbol{R}^{n}$, e.g., for the Helmholtz-operator $\Delta+k^{2}$ with $k^{2} \in \boldsymbol{R}^{+}$(cf. Wladimirow [31], pp. 143,144).

After theso considerations it is not astonishing that the application of the inverse Fourier-transform to the steps $L_{1}\left(\boldsymbol{R}^{n}, \omega_{-m}\right)\left(m \in \boldsymbol{N}_{0}\right)$ of $S_{\text {ar }}\left(\boldsymbol{R}^{n}\right)$ yields special spaces of the type $\mathscr{B}_{1, f_{k}}$ of Hörmander [18], p. 36,2,2.

Wo notio the following description of $S_{\text {ar }}\left(\boldsymbol{R}^{n}\right)$ by means of the spaces $\mathscr{D}_{L^{2}}\left(\boldsymbol{R}^{n}\right)^{\prime}$ of Schwartz [27], p. $199 \mathrm{ff}$.

(1.6) Proposrron. For $T \in \mathscr{D}\left(\boldsymbol{R}^{n}\right)^{\prime}$ the following statements are equivalent:

(a) $T \in S_{\text {ar }}\left(\boldsymbol{R}^{n}\right)$

(b) There exist $R, S \in \mathscr{D}_{L^{2}}\left(\boldsymbol{R}^{n}\right)^{\prime}$ such that $T=\mathscr{F}(R * S)$.

Proof. (a) $\Rightarrow$ (b): By (1.1), (a) implies the existence of $k \in \boldsymbol{N}_{0}$ and $h \in L^{1}\left(\boldsymbol{R}^{n}\right)$ such that

$$
T=\omega_{k} \cdot h=\omega_{k} \cdot \operatorname{sgn}(h) \cdot \sqrt{|h|} \cdot \sqrt{|h|} .
$$


We thus may put $R:=\mathscr{F}^{-1}(\operatorname{sgn}(h) \cdot \sqrt{|h|}), S:=\mathscr{F}^{-1}\left(\omega_{k} \cdot \sqrt{|h|}\right)$ and apply Schwartz [27], p. 201, Thm. XXV, p. 270, Rem., to obtain $\mathscr{F}(R * S)$ $=\mathscr{F}(R) \cdot \mathscr{F}(S)=T$.

(b) $\Rightarrow(a)$ : According to Schwartz, loc. cit., we have a representation of the form $R=\sum_{|\alpha| \leqslant l} \partial^{\alpha} f_{a}, S=\sum_{|\beta| \leqslant m} \partial^{a} g_{\beta}$ with certain functions $f_{\alpha}, g_{\beta} \in L^{2}\left(\boldsymbol{R}^{n}\right)$. We thus obtain

$$
\mathscr{F}(R * S)=\mathscr{F}(R) \cdot \mathscr{F}(S)=\sum_{\substack{|a| \leqslant l \\|\rho| \leqslant m}}(2 \pi i \hat{x})^{a+\beta} \mathscr{F}\left(f_{\alpha}\right) \cdot \mathscr{F}\left(g_{\beta}\right) \in S_{i \mathrm{ur}}\left(\boldsymbol{R}^{n}\right) .
$$

In Section 3 we will strongly use the fact that $S_{\text {ar }}\left(\boldsymbol{R}^{n}\right)$, according to (1.1c), is the Köthe-space defined by $\mathscr{S}\left(\boldsymbol{R}^{n}\right)$ in the sense of Dieudonne [10], p. 99. By $S_{\text {ar }}\left(\boldsymbol{R}^{n}\right)^{\#}$ we denote the Köthe-space defined by $S_{\mathrm{ar}}\left(\boldsymbol{R}^{n}\right)$;

(1.7) $S_{\text {ar }}\left(\boldsymbol{R}^{n}\right)^{\#}:=\left\{g \in L_{\mathrm{loc}}^{1}\left(\boldsymbol{R}^{n}\right) ; f \cdot g \in L^{1}\left(\boldsymbol{R}^{n}\right) \forall f \in S_{\text {ar }}\left(\boldsymbol{R}^{n}\right)\right\}$.

The canonical bilinear form

$$
(f, g) \mapsto\langle f, g\rangle:=\int_{\mathbf{R}^{n}} f(x) g(x) d x
$$

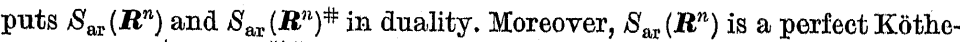
space, i.e., $\left(\mathcal{S}_{\mathrm{ar}}\left(\boldsymbol{R}^{n}\right)^{\#}\right)^{\#}=S_{\mathrm{ar}}\left(\boldsymbol{R}^{n}\right)$ (cf. Kömura [22], p. 204). With the help of (1.1) we obtain the following representation of $S_{\mathrm{ar}}\left(\boldsymbol{R}^{n}\right)^{\# \text { : }}$

(1.8) Proposition. $S_{\text {ar }}\left(\boldsymbol{R}^{n}\right)^{\#}=\bigcap_{m \in N_{0}} L^{\infty}\left(\boldsymbol{R}^{n}, \omega_{m}\right)$.

Proof. The inclusion $\bigcap_{m \in N_{0}} L^{\infty}\left(\boldsymbol{R}^{n}, \omega_{m}\right) \subset S_{a r}\left(\boldsymbol{R}^{n}\right)^{\# \#}$ is obvious. Now let $g \in S_{\text {ar }}\left(\boldsymbol{R}^{n}\right)^{\#}$. Then we have $g \cdot f \in L^{1}\left(\boldsymbol{R}^{n}\right)$ for all $f \in S_{\text {ar }}\left(\boldsymbol{R}^{n}\right)$. By (1.1b) this is equivalent to $h \cdot \omega_{k} \cdot g \in L^{1}\left(\boldsymbol{R}^{n}\right)$ for all $h \in L^{1}\left(\boldsymbol{R}^{n}\right)$ and all $k \in \boldsymbol{N}_{0}$, which implies $g \cdot \omega_{k} \in L^{\infty}\left(\boldsymbol{R}^{n}\right)$ for all $k \in \boldsymbol{N}_{0}$, i.e., $g \in \bigcap_{m \in \boldsymbol{N}_{0}} L^{\infty}\left(\boldsymbol{R}^{n}, \omega_{k}\right)$ (cf. Hewitt, Stromberg [16], p. 348, $(20,15)$ ).

2. Regular tempered distributions. In example (1.4) we saw that there are functions $f \in L_{10 \mathrm{l}}^{1}\left(\boldsymbol{R}^{n}\right) \backslash S_{\text {ar }}\left(\boldsymbol{R}^{n}\right)$, which generate tempered distributions. This motivates the following definition:

(2.1) Definimion. A tempered distribution $T \in \mathscr{S}\left(\boldsymbol{R}^{n}\right)^{\prime}$ is called. regular if $T \mid \mathscr{D}\left(\boldsymbol{R}^{n}\right)$ is represented by a locally integrable function. We denote the space of regular tempered distributions by $\boldsymbol{S}_{r}\left(\boldsymbol{R}^{n}\right)$ :

$$
S_{r}\left(\boldsymbol{R}^{n}\right):=\mathscr{S}\left(\boldsymbol{R}^{n}\right)^{\prime} \cap L_{100}^{1}\left(\boldsymbol{R}^{n}\right) .
$$

(2.2) Remarks. (a) Since $\mathscr{D}\left(\boldsymbol{R}^{n}\right)$ is dense in $\left(\mathscr{T}\left(\boldsymbol{R}^{n}\right)\right.$, $)$, a tempered distribution $T \in \mathscr{S}\left(\boldsymbol{R}^{n}\right)^{\prime}$ is uniquely determined by its restriction $T \mid \mathscr{D}\left(\boldsymbol{R}^{n}\right)$.

(b) $S_{\mathrm{r}}\left(\boldsymbol{R}^{n}\right)$ is stable in the following restricted sense with respect to differentiation: If $f \in S_{\mathbf{r}}\left(\boldsymbol{R}^{n}\right), \alpha \in \boldsymbol{N}_{0}^{n}$ and $\delta^{\alpha} f \in L_{\text {loc }}^{1}\left(\boldsymbol{R}^{n}\right)$, then we have $\partial^{a} f \in S_{\mathbf{r}}\left(\boldsymbol{R}^{n}\right)$.
Theorem VI od Schwartz [27], p. 239, together with (1.1) even yield the result: For every $f \in S_{r}\left(\boldsymbol{R}^{n}\right)$ there exists $\alpha \in \boldsymbol{N}_{0}^{n}$ and $g \in S_{\text {ar }}\left(\boldsymbol{R}^{n}\right)$ such that $f=\partial^{a} g$.

(c) In contrast to $S_{\text {ar }}\left(\boldsymbol{R}^{n}\right), S_{\mathbf{x}}\left(\boldsymbol{R}^{n}\right)$ is not a normal subspace of $L_{\text {loc }}^{1}\left(\boldsymbol{R}^{n}\right)$. According to (1.4) and (b) we have

$$
g(x):=i \cdot e^{x} \cdot \exp \left(i \cdot e^{x}\right) \in S_{r}\left(\boldsymbol{R}^{n}\right) .
$$

But $|g(x)|=e^{x}$ does not generate a tempered distribution (Schwartz [27], p. 239 , cf. also $(2.5 \mathrm{~b})$ below). The above example also shows $S_{\mathrm{ar}}\left(\boldsymbol{R}^{n}\right)$, $\subsetneq S_{\mathrm{r}}\left(\boldsymbol{R}^{n}\right) \varsubsetneqq L_{100}^{\mathrm{u}}\left(\boldsymbol{R}^{n}\right)$.

The following proposition characterizes $S_{\mathrm{r}}\left(\boldsymbol{R}^{n}\right)$.

(2.3) Propostrion. For $f \in L_{\text {loo }}^{1}\left(\boldsymbol{R}^{n}\right)$ the following statements are equivalent:

(a) $f \in S_{\mathbf{r}}\left(\boldsymbol{R}^{n}\right)$.

(b) There exists a sequence $\left(\eta_{k} ; k \in \boldsymbol{N}\right)$ in $\mathscr{D}\left(\boldsymbol{R}^{n}\right)$ satisfying (AP.1) and (AP.2) such that for all $\varphi \in \mathscr{S}\left(\boldsymbol{R}^{n}\right)$ the sequence

is convergent.

$$
\left(\int_{\boldsymbol{R}^{n}} f(x) \cdot \eta_{k}(x) \cdot \varphi(x) d x ; \eta_{i} \in \boldsymbol{N}\right)
$$

(c) $f * \psi \in \bigcup_{k \in N_{0}} L^{\infty}\left(\boldsymbol{R}^{n}, \omega_{-k}\right)$ for all $\psi \in \mathscr{D}\left(\boldsymbol{R}^{n}\right)$.

If one of these conditions is satisfied, we have

$$
\langle f, \varphi\rangle=\lim _{k \rightarrow \infty} \int_{\boldsymbol{R}^{n}} f(x) \eta_{k}(x) \varphi(x) d x \quad\left(\varphi \in \mathscr{P}\left(\boldsymbol{R}^{n}\right)\right)
$$

for every sequence $\left(\eta_{k} ; k \in \boldsymbol{N}\right)$ in $\mathscr{D}\left(\boldsymbol{R}^{n}\right)$ which satisfies (AP.1) and (AP.2).

Proof. Since $(a) \Leftrightarrow$ (c) is an obvious modification of Thm. VI, $2^{0}$ of Schwartz [27], p. 239, we comment only on the equivalence (a) $\Leftrightarrow(b)$. For every sequence $\left(\eta_{k} ; k \in \boldsymbol{N}\right)$ in $\mathscr{D}\left(\boldsymbol{R}^{n}\right)$ which satisfies (AP. 1) and (AP. 2) we have $\lim \eta_{k} \varphi=\varphi$ in $\left(\mathscr{S}\left(\boldsymbol{R}^{n}\right)\right.$, S) for all $\varphi \in \mathscr{S}\left(\boldsymbol{R}^{n}\right)$, and the existence of such sequences was established in the proof od (1.1). Thus for every $f \in S_{r}\left(\boldsymbol{R}^{n}\right)$, every approximate unit $\left(\eta_{k} ; k \in \boldsymbol{N}\right)$ and every $\varphi \in \mathscr{S}\left(\boldsymbol{R}^{n}\right)$ the sequence $\left(\left\langle f, \eta_{k} \varphi\right\rangle ; z \in \boldsymbol{N}\right)$ is convergent. On the other hand, (b) implies that $\left(\eta_{k} f ; \eta_{i} \in \boldsymbol{N}\right)$ is a $\sigma\left(\mathscr{S}^{\prime}, \mathscr{P}\right)$-Cauchy-sequence of distributions with compact support. Since $\left(\mathscr{S}\left(\boldsymbol{R}^{n}\right), \mathfrak{S}\right)$ is barrelled, this sequence has a limit in $\mathscr{S}\left(\boldsymbol{R}^{n}\right)^{\prime}$, which obviously must be $f$.

In $(2.2 \mathrm{c})$ we saw that $S_{\mathrm{r}}\left(\boldsymbol{R}^{n}\right)$ is not a normal subspace of $L_{10 \mathrm{c}}^{1}\left(\boldsymbol{R}^{n}\right)$. Now we show that the normal hull

$$
\mathcal{N}\left(S_{\mathrm{r}}\left(\boldsymbol{R}^{n}\right)\right):=\left\{g \in L_{\mathrm{loc}}^{1}\left(\boldsymbol{R}^{n}\right) ; \exists f \in S_{\mathrm{r}}\left(\boldsymbol{R}^{n}\right):|g(x)| \leqslant|h(x)| \text { a.e. on } \boldsymbol{R}^{n}\right\}
$$

of $S_{\mathrm{r}}\left(\boldsymbol{R}^{n}\right)$ is all of $L_{\mathrm{loo}}^{1}\left(\boldsymbol{R}^{n}\right)$. 
(2.4) Propostition. $\mathscr{N}\left(S_{\mathrm{r}}\left(\boldsymbol{R}^{n}\right)\right)=L_{\mathrm{loc}}^{1}\left(\boldsymbol{R}^{n}\right)$.

Proof. The proof will be given in three steps.

(a) $\mathcal{N}\left(S_{\mathbf{r}}\left(\boldsymbol{R}^{n}\right)\right) \supset I_{\text {loc }}^{\infty}\left(\boldsymbol{R}^{n}\right)$. For $\alpha \in Z^{n}$, we define $A(\alpha):=\left[\alpha_{1}, \alpha_{1}+1\right) \times \ldots$ $\ldots \times\left[\alpha_{n}, \alpha_{n}+1\right)$. Let $g \in L_{\text {loc }}^{\infty}\left(\boldsymbol{R}^{n}\right)$ be given. We put $M_{\alpha}:=$ ess $\operatorname{lop}|g|$ and choose $m(\alpha) \in \boldsymbol{N}$ such that $M_{a}<2^{m(\alpha)}\left(\alpha \in \boldsymbol{Z}^{n}\right)$. Let $h: \boldsymbol{R}^{n} \rightarrow \boldsymbol{R}$ be defined by

$$
h(x):=(-1)^{j} M_{a} \text { for } x \in A(\alpha) \text { and } x_{1} \in\left[\alpha_{1}+2^{-m(\alpha)} j, \alpha_{1}+2^{-n(\alpha)}(j+1)\right)
$$

$$
\left(\alpha \in \boldsymbol{Z}^{n}, j \in\left\{0, \ldots, 2^{m(a)}-1\right\}\right) .
$$

We obviously have $h \in L_{\text {loo }}^{\infty}\left(\boldsymbol{R}^{n}\right)$ and $|g(x)| \leqslant|h(x)|$ a.e. on $\boldsymbol{R}^{n}$. Now define $f: \boldsymbol{R}^{n} \rightarrow \boldsymbol{R}$ by

$$
f(x):=\int_{0}^{x_{1}} h\left(y, x_{2}, \ldots, x_{n}\right) d y \quad\left(x \in \boldsymbol{R}^{n}\right) .
$$

Then $\partial_{1} f=h$ and according to $(2.2 \mathrm{~b})$ the result $h \in S_{\mathrm{r}}\left(\boldsymbol{R}^{n}\right)$ will follows from $f \in S_{\text {ar }}\left(\boldsymbol{R}^{n}\right)$. The latter is true since an easy calculation shows $0 \leqslant f(x)<1$ for all $x \in \boldsymbol{R}^{n}$.

(b) $L_{\text {loc }}^{\infty}\left(\boldsymbol{R}^{n}\right)+L^{1}\left(\boldsymbol{R}^{n}\right)=L_{\text {loc }}^{1}\left(\boldsymbol{R}^{n}\right)$. Let $(a(m) ; m \in \boldsymbol{N})$ be an enumeration of $\boldsymbol{Z}^{n}$ and let $A(m):=A(\alpha(m))$ be defined as above $(m \in \boldsymbol{N})$. By $\chi_{m}$ we denote the characteristic function of $A(m)(m \in \boldsymbol{N})$. Lot $f \in L_{100}^{1}\left(\boldsymbol{R}^{n}\right)$ be given. Because of $f \cdot \chi_{m} \in L^{1}(A(m))$ there exists $g_{m} \in L^{\infty}(A(m))$ such that $\left\|f \cdot \chi_{m}-g_{m}\right\|_{1} \leqslant 2^{-m} \quad(m \in \boldsymbol{N})$. Thus

$$
f(x)=\sum_{m \in \mathbf{N}} g_{m}(x)+\sum_{m \in \mathbf{N}}\left(f(x) \cdot \chi_{m}(x)-g_{m}(x)\right) \quad\left(x \in \boldsymbol{R}^{n}\right)
$$

is a decomposition for $f$ of the required form.

(c) Now we prove (2.4). (This proof is due to S. Dierolf.) Let $f \in L_{100}^{1}\left(\boldsymbol{R}^{n}\right)$ be given. By (b) there exist $g \in I_{\mathrm{log}}^{\infty}\left(\boldsymbol{R}^{n}\right)$ and $h \in I^{1}\left(\boldsymbol{R}^{n}\right)$ such that $f=g+h$. According to (a) there exists $g_{1} \in S_{\mathrm{r}}\left(\boldsymbol{R}^{n}\right)$ such that $\left|g_{1}(x)\right| \geqslant|g(x)|$ a.e. on $\boldsymbol{R}^{n} . h \in L^{1}\left(\boldsymbol{R}^{n}\right)$ implies

$$
\operatorname{sgn}\left(g_{1}\right) \cdot|h| \in L^{1}\left(\boldsymbol{R}^{n}\right) \subset S_{\mathrm{r}}\left(\boldsymbol{R}^{n}\right),
$$

we thus obtain $h_{1}:=g_{1}+\operatorname{sgn}\left(g_{1}\right) \cdot|h| \in S_{\mathbf{r}}\left(\boldsymbol{R}^{n}\right)$. Now wo have the following estimate:

$$
\begin{aligned}
\left|h_{1}(x)\right| & =\left|\operatorname{sgn}\left(g_{1}(x)\right) \cdot\right| g_{1}(x) \mid+\operatorname{sgn}\left(g_{1}(x)|\cdot| h(x)||\right. \\
& =\left|g_{1}(x)\right|+|h(x)| \geqslant|g(x)|+|h(x)| \geqslant|g(x)+h(x)|=|f(x)|
\end{aligned}
$$

a.e. on $\boldsymbol{R}^{n}$. This proves $f \in \mathscr{N}\left(S_{\mathrm{r}}\left(\boldsymbol{R}^{n}\right)\right)$.

(2.5) Remarks. (a) From (2.4) we see that $f \in S_{\mathrm{r}}\left(\boldsymbol{R}^{n}\right)$ does not imply any growth condition for $|f|$. On the other hand, according to $(2.3 \mathrm{c})$ the regularizations $f * \psi\left(\psi \in \mathscr{D}\left(\boldsymbol{R}^{n}\right)\right)$ of $f \in \mathbb{S}_{\mathrm{r}}\left(\boldsymbol{R}^{n}\right)$ must not grow too fast.
This gives the following intuitive picture of the elements $f \in S_{\mathbf{r}}\left(\boldsymbol{R}^{n}\right)$ : The faster $|f|$ "growth", the faster $f$ has to oscillate.

Moreover, (2.4) shows that for the calculation of $\langle f, p\rangle\left(f \in S_{\mathrm{r}}\left(\boldsymbol{R}^{n}\right)\right.$, $\left.\varphi \in \mathscr{S}\left(\boldsymbol{R}^{n}\right)\right)$ according to (2.3b) one has to use an approximate unit consisting of functions with compact support.

(b) From Lomma (3.2a) it follows in particular:

$$
\forall \varphi \in \mathscr{S}\left(\boldsymbol{R}^{n}\right) \exists \psi \in \mathscr{T}\left(\boldsymbol{R}^{n}\right):|p| \leqslant \psi .
$$

Now let $f \in S_{x}\left(\boldsymbol{R}^{n}\right), f \geqslant 0, \psi \in \mathscr{T}\left(\boldsymbol{R}^{n}\right), \psi \geqslant 0$. Then (2.3b) and Fatou's lemma yield $f \cdot \psi \in L^{1}\left(\boldsymbol{R}^{n}\right)$ (ef. the proof of $(1.1 \mathrm{a}) \Rightarrow(1.1 \mathrm{~b})$ ). We thus obtain $f \in S_{\text {ar }}\left(\boldsymbol{R}^{n}\right)$, i.e. $S_{\mathrm{r}}\left(\boldsymbol{R}^{n}\right)^{+*}=L_{\text {loo }}^{1}\left(\boldsymbol{R}^{n}\right)^{+} \cap \mathscr{S}\left(\boldsymbol{R}^{n}\right)^{\prime}=S_{\text {ar }}\left(\boldsymbol{R}^{n}\right)^{+}$.

3. The locally convex structure of $S_{\mathrm{ar}}\left(\boldsymbol{R}^{n}\right)$. The structure of the space $S_{\text {ar }}\left(\boldsymbol{R}^{n}\right)$ suggests several natural possibilities to provide this space with a locally convex topology. The next proposition shows that these definitions lead to the same topology.

(3.1) Proposrrion. On $S_{\text {ar }}\left(\boldsymbol{R}^{n}\right)$ the following topologies coincide:

(a) the LB-space topology $\mathfrak{I}$ defined by

$$
\bigcup_{k \in N_{0^{\prime}}}\left(L^{1}\left(\boldsymbol{R}^{n}, \omega_{-l_{i}}\right),\|\cdot\|_{1,-k}\right)
$$

(b) the Mackey-topotogy $\tau\left(S_{\mathrm{ar}}, S_{\mathrm{an}}\right)$ (cf. (1.7) for the definition of $\left.S_{\mathrm{ar}}^{\#}\right)$;

(c) the locally convex topology $\mathfrak{I}_{1}$, which is generated by the semi-norms $p_{g}(f):=\|f \cdot g\|_{1}\left(f \in S_{\text {ar }}\left(\boldsymbol{R}^{n}\right), g \in S_{a \mathrm{r}}\left(\boldsymbol{R}^{n}\right)^{\#}\right) ;$

(d) the tocally convex topotogy $\mathfrak{I}_{2}$, which is generated by the semi-norms $\left(p_{p} ; \varphi \in \mathscr{S}\left(\boldsymbol{R}^{n}\right), \varphi \geqslant 0\right)$;

(e) the strong topology $\beta\left(S_{\text {ar }} ; D\right)$.

Proof. We first show $\mathfrak{I}=\tau\left(S_{a n}, S_{a r}^{\#}\right)$. Obviously $\mathscr{D}\left(\boldsymbol{R}^{n}\right)$ is dense in each space $\left(L^{\mathrm{I}}\left(\boldsymbol{R}^{n}, \omega_{-k}\right),\|\cdot\|_{1,-k}\right) \quad\left(k_{i} \in \boldsymbol{N}_{0}\right)$, and $\mathfrak{I} \cap \mathscr{D}\left(\boldsymbol{R}^{n}\right)$ is coarser than the standard topology of $\mathscr{D}\left(\boldsymbol{R}^{n}\right)$. Thus we may identify the dual $\left(S_{\mathrm{ar}}\left(\boldsymbol{R}^{n}\right), \mathfrak{I}\right)^{\prime}$ with a subspace of $\mathscr{D}\left(\boldsymbol{R}^{n}\right)^{\prime}$. Since $\mathfrak{I}$ is the locally convex final topology on $S_{\mathrm{ar}}\left(\boldsymbol{R}^{n}\right)$ with respect to the inclusions

$$
j_{k}:\left(L^{1}\left(\boldsymbol{R}^{n}, \omega_{-k}\right),\|\cdot\|_{1,-y_{k}}\right) C_{\rightarrow} S_{\text {ar }}\left(\boldsymbol{R}^{n}\right) \quad\left(k \in \boldsymbol{N}_{0}\right),
$$

a distribution $T \in \mathscr{D}\left(\boldsymbol{R}^{n}\right)^{\prime}$ is $\mathfrak{I} \cap \mathscr{D}\left(\boldsymbol{R}^{n}\right)$-continuous if and only if $T$ is continuous on each space $\left(\mathscr{D}\left(\boldsymbol{R}^{n}\right),\|\cdot\|_{1,-k}\right)\left(k \in \boldsymbol{N}_{0}\right)$. Since the dual space of $\left(\mathscr{D}\left(\boldsymbol{R}^{n}\right),\|\cdot\|_{1,-k}\right)$ is $L^{\infty}\left(\boldsymbol{R}^{n}, \omega_{k}\right)\left(7_{i} \in \boldsymbol{N}_{0}\right)$, we thus obtain

$$
\left(S_{\mathrm{ar}}\left(\boldsymbol{R}^{n}\right), \mathfrak{T}\right)^{\prime}=\bigcap_{k \in \mathbf{N}_{0}} L^{\infty}\left(\boldsymbol{R}^{n}, \omega_{k}\right)=S_{\mathrm{ar}}\left(\boldsymbol{R}^{n}\right)^{\#} .
$$

As the LB-space $\left(S_{\mathrm{ar}}\left(\boldsymbol{R}^{n}\right), \mathfrak{T}\right)$ is barrelled, we infer $\mathfrak{I}=\beta\left(\mathcal{S}_{\mathrm{ar}}, S_{\mathrm{ar}}^{\#}\right)$ $=\tau\left(S_{\mathrm{ar}}, S_{\mathrm{ar}}^{\#}\right)$. From now on we write $S_{\mathrm{ar}}^{\prime}$ instead of $S_{\mathrm{ar}}^{\#}$. The coincidence 
of the topologies $\mathfrak{I}, \mathfrak{I}_{1}$, and $\mathfrak{I}_{2}$ will be proved with the help of the following lemma.

(3.2) Lemva. (a) Let $B \subset S_{\mathrm{ar}}^{\prime}$ be $\sigma\left(S_{\mathrm{ar}}^{\prime}, S_{\mathrm{ar}}\right)$-bounded. Then there exists $\varphi \in \mathscr{S}\left(\boldsymbol{R}^{n}\right), \varphi \geqslant 0$ such that

$$
B \subset \mathscr{N}(\varphi)=\left\{g \in L_{\mathrm{loc}}^{1}\left(\boldsymbol{R}^{n}\right) ;|g(x)| \leqslant \varphi(x) \text { a.e. on } \boldsymbol{R}^{n}\right\} .
$$

(b) For $g \in S_{\mathrm{an}}^{\prime}$ the set $\mathscr{N}(g)$ is absotutely convex and $\sigma\left(S_{\mathrm{ar}}^{\prime}, S_{\mathrm{ar}}\right)$-closed.

(c) The system $\mathfrak{M}:=\left\{B \subset S_{\mathrm{ar}}^{\prime} ; \exists \varphi \in \mathscr{S}\left(\boldsymbol{R}^{n}\right), \varphi \geqslant 0\right.$ such that $\left.B \subset \mathscr{N}(\varphi)\right\}$ is saturated (in the sense of Köthe [20], p. 255) and coincides with the I-equicontinuous subsets of $S_{\mathrm{ar}}^{\prime}$.

We postpone the proof of (3.2) and continue the proof of (3.1). The inclusions $\mathfrak{I} \supset \mathfrak{I}_{1} \supset \mathfrak{I}_{2}$ are easy to verify. Now let $H \subset S_{\mathrm{ar}}^{\prime}$ be $\mathfrak{T}$-equicontinuous. We show $H^{0} \in \mathfrak{U}_{0}\left(\mathcal{S}_{\mathrm{ar}}\left(\boldsymbol{R}^{n}\right), \mathfrak{I}_{2}\right)$. According to (3.2) there exists $\varphi \in \mathscr{S}\left(\boldsymbol{R}^{n}\right), \varphi \geqslant 0$ such that $\mathbb{H} \subset \mathcal{N}(\varphi)$. This implies

$$
\mathscr{N}(\varphi)^{0} \subset H^{0} \in \mathfrak{U}_{0}\left(\mathcal{S}_{\mathrm{ar}}\left(\boldsymbol{R}^{n}\right), \mathfrak{T}\right) .
$$

It is therefore sufficient to prove

$$
\begin{aligned}
U_{\varphi} & :=\left\{f \in S_{\mathrm{ar}}\left(\mathbf{R}^{n}\right) ; p_{\varphi}(f) \leqslant 1\right\} \subset \mathscr{N}(\varphi)^{0} . \\
f \in U_{\varphi}, h \in \mathcal{N}(\varphi) & \Rightarrow\left|\int_{\mathbf{R}^{n}} f(x) \cdot h(x) d x\right| \leqslant \int_{\mathbf{R}^{n}}|f(x)| \varphi(x) d x=p_{\varphi}(f) \leqslant 1 \\
& \Rightarrow U_{\varphi} \subset \mathcal{N}(\varphi)^{0} .
\end{aligned}
$$

(Actually $U_{\varphi}=\mathscr{N}(\varphi)^{0}$ holds.) We thus have proved $\mathfrak{I}=\mathfrak{I}_{1}=\mathfrak{I}_{2}$.

To prove $\mathfrak{I}=\beta\left(S_{\mathrm{ar}}, \mathscr{D}\right)$ we have to show: Each $\sigma\left(S_{\mathrm{ar}}^{\prime}, S_{\mathrm{ar}}\right)$-bounded subset $B$ of $S_{\mathrm{ar}}^{\prime}$ is contained in the $\sigma\left(S_{\mathrm{ar}}^{\prime}, S_{\mathrm{ar}}\right)$-closure of a $\sigma\left(\mathscr{D}, S_{\mathrm{ar}}\right)$ bounded subset of $\mathscr{D}\left(\boldsymbol{R}^{n}\right)$. Let $B \subset S_{\mathrm{ar}}^{\prime}$ be $\sigma\left(S_{\mathrm{ar}}^{\prime}, S_{\mathrm{ar}}\right)$-bounded. Then $B$ is also $\beta\left(S_{\mathrm{ar}}^{\prime}, S_{\mathrm{ar}}\right)$-bounded (Horváth [19], p. 212, Cor.). According to Köthe $[20]$, p. $402,(4)$, the strong topology $\beta\left(S_{\mathrm{ar}}^{\prime}, S_{\mathrm{ar}}\right)$ coincides with the supremum $\bigvee_{k \in \mathbf{N}_{0}} \beta\left(I^{\infty}\left(\boldsymbol{R}^{n}, \omega_{k}\right), L^{1}\left(\boldsymbol{R}^{n}, \omega_{-k}\right)\right)$ and $\beta\left(L^{\infty}\left(\boldsymbol{R}^{n}, \omega_{k}\right)\right.$, $\left.L^{1}\left(\boldsymbol{R}^{n}, \omega_{-k}\right)\right)$ is generated by the norm \|\|$_{\infty, k}\left(k_{k} \in \boldsymbol{N}_{0}\right)$. Thus there exists a sequence $\left(a_{k} ; k \in \boldsymbol{N}_{0}\right)$ in $\boldsymbol{R}^{+}$such that $\|g\|_{\infty, k} \leqslant a_{k}\left(k_{k} \in \boldsymbol{N}_{0}, g \in B\right)$. The usual cutting and regularization process provides us with a sequence $\left(R_{m} ; m \in \mathbf{N}\right)$ of linear operators

$$
R_{m}: S_{\mathrm{ar}}\left(\boldsymbol{R}^{n}\right)^{\prime} \rightarrow \mathscr{D}\left(\boldsymbol{R}^{n}\right) \quad(m \in \boldsymbol{N})
$$

such that

$$
\begin{aligned}
& \text { (i) }\left\|R_{m}(g)\right\|_{\infty, k} \leqslant 4^{k_{k}}\|g\|_{\infty, k}\left(k \in \boldsymbol{N}_{0}, m \in \boldsymbol{N}, g \in \boldsymbol{S}_{\text {ar }}\left(\boldsymbol{R}^{n}\right)^{\prime}\right), \\
& \text { (ii) } \left.\left|R_{m}(g)(x) \cdot f(x)\right| \leqslant 4^{k \cdot}\|g\|_{\infty, k i} \mid f(x)\right\} \cdot \omega_{k b}(x) \text { a.e. on } \boldsymbol{R}^{n} \text { for all } g \in \boldsymbol{S}_{\text {ar }}\left(\boldsymbol{R}^{n}\right)^{\prime} \text {, }
\end{aligned}
$$
$f \in L^{1}\left(\boldsymbol{R}^{n}, \omega_{-l_{k}}\right), l_{i} \in \boldsymbol{N}_{0}, m \in \boldsymbol{N}$,

(iii) $\lim R_{m}(g)(x)=g(x)$ a.e. on $\boldsymbol{R}^{n}\left(g \in \mathbb{S}_{\mathrm{ar}}\left(\boldsymbol{R}^{n}\right)^{\prime}\right)$.
The dominated convergence theorem thus implies $\lim _{m \rightarrow \infty} R_{m}(g)=g$ with respect to $\sigma\left(S_{\text {ar }}^{\prime}, S_{\text {ar }}\right)$ for all $g \in S_{\text {ar }}\left(\boldsymbol{R}^{n}\right)^{\prime}$. Thus $B$ is contained in the $\sigma\left(S_{\text {ary }}^{\prime}, S_{\text {ar }}\right)$-closure of the $\sigma\left(\mathscr{D}, S_{\text {ax }}\right)$-bounded set

$$
\left\{p \in \mathscr{D}\left(\boldsymbol{R}^{n}\right) ;\|p\|_{\infty, \pi} \leqslant 4^{k} a_{l l}\left(7_{i} \in \boldsymbol{N}_{0}\right)\right\} .
$$

We now prove Lemma (3.2).

Ad (3.2a): Let $B \subset S_{\text {ar }}\left(\boldsymbol{R}^{n}\right)^{\prime}$ be $\sigma\left(S_{\mathrm{ar}}^{\prime}, S_{\mathrm{ar}}^{\prime}\right)$-bounded. As in the last proof we find. a sequence $\left(a_{f i} ; z_{i} \in \boldsymbol{N}_{0}\right)$ in $\boldsymbol{R}^{+}$such that $\|g\|_{\infty, r_{i}} \leqslant a_{k_{i}}\left(k_{i} \in \boldsymbol{N}_{0}, g \in \mathcal{B}\right)$. We choose $\eta \in \mathscr{D}\left(\boldsymbol{R}^{n}\right)$ such that

$0 \leqslant \eta(x) \leqslant 1\left(x \in \boldsymbol{R}^{n}\right), \quad \eta(x)=1$ for $|x| \leqslant 1, \quad \eta(x)=0$ for $|x| \geqslant 2$ hold and define $\eta_{m(}(x):=\eta\left(x / 2^{m}\right)\left(x \in \boldsymbol{R}^{n}, m \in \boldsymbol{N}\right), \theta_{1}(x):=\eta_{1}(x), \theta_{m}(x)$ $:=\eta_{m}(x)-\eta_{m-1}(x)\left(x \in \boldsymbol{R}^{n}, m \geqslant 2\right)$. The following properties of the sequence $\left(\theta_{m} ; m \in \boldsymbol{N}\right)$ are easy to verify:

(i) $\operatorname{supp}\left(\theta_{m}\right) \subset\left\{x \in \boldsymbol{R}^{n} ; 2^{m-1} \leqslant|x| \leqslant 2^{m+1}\right\}(m \geqslant 2)$.

(ii) $|m-l|>2 \Rightarrow \operatorname{supp}\left(\theta_{m}\right) \cap \operatorname{supp}\left(\theta_{l}\right)=\varnothing(m, l \in \boldsymbol{N})$.

(iii) $\theta_{m}(x) \geqslant 0\left(x \in \boldsymbol{R}^{n}, m \in \boldsymbol{N}\right), \sum_{m \in \mathbb{N}} \theta_{m}(x)=1 \quad\left(x \in \boldsymbol{R}^{n}\right)$.

(iv) $\forall \alpha \in \boldsymbol{N}_{0}^{n} \exists O_{\alpha}>0 \forall x \in \boldsymbol{R}^{n}, m \in \boldsymbol{N}:\left|\partial^{\alpha} \theta_{m}(x)\right| \leqslant O_{\alpha} \omega_{-|\alpha| / 2}(x)$.

We now define $b_{m}:=\sup \{\operatorname{esssup}|g| ; g \in B\}(m \in \boldsymbol{N})$ and obtain the following estimate:

$$
\begin{aligned}
a_{k l} & \left.\geqslant \sup \left\{\underset{\boldsymbol{R}^{n}}{\operatorname{exssup}}\left|g \cdot \omega_{k}\right| ; g \in B\right\} \geqslant \sup \underset{\operatorname{supp}\left(\theta_{m}\right)}{\operatorname{esssup}}\left|g \cdot \omega_{k}\right| ; g \in B\right\} \\
& \geqslant\left(1+2^{2(m-1)}\right)^{k} \cdot \sup \left\{\underset{\text { supp }\left(\theta_{m}\right)}{\operatorname{esssup}}|g| ; g \in B\right\} \geqslant 2^{2 k(m-1)} b_{m}
\end{aligned}
$$

$\left(l_{\in} \in \boldsymbol{N}_{0}, m \in \boldsymbol{N}\right.$ ). Using (iv) we thus obtain the estimate

$$
\begin{aligned}
\omega_{k}(x) \cdot \sum_{j \leqslant m \ll l} b_{m}\left|\partial^{\alpha} \theta_{m}(x)\right| & \leqslant \sum_{j \leqslant m \leqslant l} b_{m} \cdot\left(1+2^{2(m+1)}\right)^{k} \cdot O_{a} \\
& \leqslant O_{a} \cdot \sum_{j \leqslant m \leqslant l} b_{m} \cdot 2^{22 k m+3 k} \leqslant O_{a} \cdot a_{k+1} \cdot 2^{5 k+2} \cdot \sum_{j \leqslant m \leqslant l}\left(2^{-2}\right)^{m}
\end{aligned}
$$

$\left(\infty \in \boldsymbol{R}^{n}, l \in \boldsymbol{N}_{0}, j, l \in \boldsymbol{N}, j \leqslant l, \alpha \in \boldsymbol{N}_{0}^{n}\right)$. This shows that the sequence $\left(\sum_{m \in l} b_{m} \cdot \theta_{m} ; l \in \boldsymbol{N}\right)$ is convergent in $\left(\mathscr{S}\left(\boldsymbol{R}^{n}\right), \mathbb{S}\right), \varphi:=\sum_{m \in l} b_{m} \theta_{m}$. With the help of (iii) wo obtain

$$
\begin{aligned}
|g(x)| & =\left|\sum_{m \in \mathbb{N}} g(x) \cdot \theta_{m}(x)\right| \leqslant \sum_{m \in \mathbf{N}}|g(x)| \cdot \theta_{m}(x) \\
& \left.\leqslant \sum_{m \in \mathbb{N}}\left(\underset{\sup }{\operatorname{sesssup}\left(\sup _{m}\right)}|h| ; h \in B\right\}\right) \cdot \theta_{m}(x)=\varphi(x)
\end{aligned}
$$

a.e. on $\boldsymbol{R}^{n}$ for all $g \in B$. 
Ad (3.2b): Obviously $\mathcal{N}(g)$ is absolutely convex. Now let $\left(g_{i} ; \iota \in I\right)$ be a net in $\mathcal{N}(g)$ which converges with respect to $\sigma\left(S_{\text {ar }}^{\prime}, S_{\text {ar }}\right)$ to $h \in S_{\text {ar }}^{\prime}$ and suppose $h \notin \mathscr{N}(g)$. Then there exists $m \in \boldsymbol{N}$ and a compact set $K \subset \boldsymbol{R}^{n}$ of measure $\lambda(K)>0$ such that $|h(x)|>|g(x)|+m^{-1}$ for all $x \in K$. Let $\chi_{K}$ denote the characteristic function of $K$. Since $\chi_{K} \cdot \operatorname{sgn} h \in S_{\mathrm{ar}}$, the estimate

$$
\int_{\boldsymbol{R}^{n}} h(x) \cdot \operatorname{sgn}(h(x)) \cdot \chi_{K}(x) d x=\int_{K}|h(x)| d x \geqslant \int_{K}|g(x)| d x+m^{-1} \cdot \lambda(K)
$$

contradicts the estimate

$$
\left|\int_{\boldsymbol{R}^{n}} g_{\iota}(x) \cdot \operatorname{sgn}(h(x)) \cdot \chi_{K}(x) d x\right| \leqslant \int_{K}\left|g_{\iota}(x)\right| d x \leqslant \int_{K^{K}}|g(x)| d x \quad(\iota \in I) .
$$

Thus we have $h \in \mathcal{N}(g)$.

Ad (3.2c): Using (3.2b) and the relations $\mathscr{N}(\mu \cdot \varphi)=\mu \cdot \mathscr{N}(\varphi), \mu \cdot \mathcal{N}\left(\varphi_{1}\right)+$ $+\nu \cdot \mathcal{N}\left(\varphi_{2}\right) \subset \mathscr{N}\left(|\mu| \varphi_{1}+|\nu| \varphi_{2}\right)\left(\mu, \nu \in \boldsymbol{C}, p, \phi_{1}, p_{2} \in \mathscr{P}\left(\boldsymbol{R}^{n}\right)^{+}\right)$we obtain that $\mathfrak{M}$ is saturated. From $\mathfrak{T}=\beta\left(S_{\mathrm{ar}}, S_{\mathrm{ar}}^{\prime}\right)$ we infer that $H \subset S_{\mathrm{ar}}^{\prime}$ is $\mathfrak{I}$-equicontinuous if and only if $H$ is $\sigma\left(S_{\mathrm{ar}}^{\prime}, S_{\mathrm{ar}}\right)$-bounded. Since the sets $\mathcal{N}(p)$ $\left(\varphi \in \mathscr{S}\left(\boldsymbol{R}^{n}\right)^{+}\right)$are obviously $\sigma\left(S_{\mathrm{ar}}^{\prime}, S_{\mathrm{ar}}\right)$-bounded, (3.2a) implies that $\mathfrak{I}$ is the topology of uniform convergence on all sets in M. Now the assertion follows from Köthe [20], p. 256, (4).

(3.3) Remarks. A result related to (3.2a) was first proved by Roider [25] p. 330 , in a different way. Special cases were treated by Chevalley $[3]$, p. 127 and Szmydt $[30]$, p. 155, Exercise 17. The result (3.2a) in particular implies $S_{\mathrm{ar}}\left(\boldsymbol{R}^{n}\right)^{\prime}=\mathscr{N}\left(\mathscr{S}\left(\boldsymbol{R}^{n}\right)\right)$.

Proposition (3.1) allows us to combine the theory of LB-spaces and the theory of the Köthe-spaces (in the sense of Dieudonne [10]) to obtain a rather complete description of $\left(S_{\text {ar }}\left(\boldsymbol{R}^{n}\right), \mathfrak{I}\right)$. This will be given in the next theorem.

(3.4) THEOREM. (a) $\left(S_{\mathrm{ar}}\left(\boldsymbol{R}^{n}\right), \mathfrak{I}\right)$ is a complete LB-space.

(b) $\left(S_{\mathrm{ar}}\left(\boldsymbol{R}^{n}\right), \sigma\left(S_{\mathrm{ar}}, \mathcal{S}_{\mathrm{ar}}^{\prime}\right)\right)$ is sequentially complete.

(c) If $B \subset S_{\mathrm{ar}}\left(\boldsymbol{R}^{n}\right)$ is $\mathfrak{I}$-bounded, there exists $k \in \mathbf{N}_{0}$ suoh that $B \subset$ $L^{1}\left(\boldsymbol{R}^{n}, \omega_{-k}\right)$ and is $\|\cdot\|_{1,-k}$-bounded.

(d) For every compact set $K \subset \boldsymbol{R}^{n},\left(L^{1}(K),\|\cdot\|_{1}\right)$ is a complemented subspace of $\left(L^{1}\left(\boldsymbol{R}^{n}, \omega_{-k}\right),\|\cdot\|_{1,-k}\right)\left(k_{i} \in \boldsymbol{N}_{0}\right)$ and of $\left(S_{\mathrm{ar}}\left(\boldsymbol{R}^{n}\right), \mathfrak{I}\right)$. The same holds for the corresponding weak topologies.

(e) If $B$ is bounded in $\left(L^{1}\left(\boldsymbol{R}^{n}, \omega_{-k}\right),\|\cdot\|_{1,-k}\right)$, then $\mathfrak{I}$ and $\|\cdot\|_{1,-(i+1)}$ induce the same topology on $\mathcal{B}$. The same holds for the corresponding weak topologies.

Proof. (a) and (b): It follows from (3.1d) that $\left(S_{\mathrm{ar}}\left(\boldsymbol{R}^{n}\right), \mathfrak{I}\right)$ is the projective limit of the system

$$
\left(\left(\left(L^{1}\left(\boldsymbol{R}^{n}, \varphi\right), p_{\varphi}\right) ; \varphi \in \mathscr{S}\left(\boldsymbol{R}^{n}\right), \varphi(x)>0 \forall x \in \boldsymbol{R}^{n}\right)\right.
$$

and that $\sigma^{\prime}\left(S_{\text {ar }}, S_{a r}^{\prime}\right)$ is the projective limit of the corresponding weak topologies (cf. Köthe $[20]$, p. 292, (6)). Now the assertions (a) and (b) follow from Köthe $[20]$, p. 232, 10. (2) and Dieudonne [10], p. 92, Cor.

(c) follows from (a) (cf. Kötho [20], p. 225, (5)).

(d) follows immodiatoly from the propertios of the woight functions $\omega_{-k}\left(k \in \mathbb{N}_{0}\right)$.

(e) Lot $B \subset L^{1}\left(\mathbb{R}^{n}, \omega_{\ldots k}\right)$ bo \|\|$_{1,-l_{i}}$ bounded and absolutely convox. Clearly, $\mathfrak{I} B$ is coarsor than the topology induced by $\|\cdot\|_{1,-(c+1)}$ on $B$. To prove the rovorso inclusion it is sufficient to show: Fvery not $\left(f_{i} ; \iota \in I\right)$ in $B$ which $\mathfrak{z}$-convorges to 0 also converges to 0 with respect to $\|\cdot\|_{1,-(k+1)}$ (cf. Grothandieck [14], p. 134).

Let $\varepsilon>0$ bo given. From $\left\|f_{\imath}\right\|_{1,-l i} \leqslant O(\iota \in I)$ we obtain the estimate

$$
\begin{aligned}
\int_{|x|>l}\left|f_{l}(x)\right| \cdot \omega_{-(l+1)}(x) d x & \leqslant\left(1+l^{2}\right)^{-1} \int_{|x|>l}\left|f_{l}(x)\right| \omega_{-h}(x) d x \\
& \leqslant\left(1+l^{2}\right)^{-1} \cdot \varnothing \quad(\iota \in I, l \in \mathbf{N}) .
\end{aligned}
$$

Wo choose $l \in \boldsymbol{N}$ such that $\left(1+l^{2}\right)^{-1} \cdot O \leqslant \varepsilon / 2$. Since $K:=\left\{x \in \boldsymbol{R}^{n} ;|x| \leqslant l\right\}$ is compact, it follows from (d) that there exists $x \in I$ such that

$$
\int_{\mathcal{K}}\left|f_{4}(x)\right| \omega_{-(k+1)}(x) d x \leqslant \varepsilon / 2
$$

holds for all $\iota \geqslant \varkappa$. We thus obtain $\left\|f_{\iota}\right\|_{x,-(l+1)} \leqslant \varepsilon$ for all $\iota \geqslant x$. The proof for the corresponding weak topologies is similar.

(3.5) Remarks. (a) It follows from (3.4c) and (3.4e) that $\bigcup_{k \in N_{0}}\left(L^{1}\left(\boldsymbol{R}^{n}\right.\right.$, $\left.\left.\omega_{-k}\right),\|\cdot\|_{1,-k_{k}}\right)$ is strongly boundedly retractive and therefore also compactly regular and sequentially retractive (cf. Bierstedt, Meise [2], p. 100).

(b) It follows from $(3.4 \mathrm{~d})$ that $\left(\mathcal{S}_{\mathrm{ar}}\left(\boldsymbol{R}^{n}\right), \mathfrak{T}\right)$ is neither a Schwartzspaco (Horvath [19], p. 278, Prop. 6 (a)), nor semi-reflexive (Köthe [20], p. $299,(5))$.

(c) A routine calculation shows that $\left(S_{\text {arr }}\left(\boldsymbol{R}^{n}\right), \mathfrak{I}\right)$ has the approximation property with respect to cutting and regularization (Schwartz [49], Oh. I, p. 7/8), and thus also has the strict approximation property (loc. cit. p. 5 and p. 9).

4. Locally convex topologies on $S_{x}\left(\boldsymbol{R}^{n}\right)$. There are two natural locally convex topologies on $S_{r}\left(\boldsymbol{R}^{n}\right)$. To describe these topologies we use the Hilbert-spaces $\left(H_{q} ; q \in Z Z\right)$ which were introduced by Kučera [23]. A detailed treatment of these spaces is given in [6], §14. 
For $q \in \boldsymbol{N}_{0}$ we put

$$
\begin{gathered}
H_{q}:=H_{q}\left(\boldsymbol{R}^{n}\right):=\left\{f \in I^{2}\left(\boldsymbol{R}^{n}\right) ; \hat{x}^{\alpha} \partial^{\beta} f \in L^{2}\left(\boldsymbol{R}^{n}\right) \forall \alpha, \beta \in \boldsymbol{N}_{0}^{n},|\alpha+\beta| \leqslant q\right\}, \\
{[f, g]_{(q)}:=\sum_{|\alpha+\beta| \leqslant q} \int_{\boldsymbol{R}^{n}}\left(x^{\alpha} \partial^{\beta} f(x)\right) \overline{\left(x^{\alpha} \partial^{\beta} g(x)\right)} d x \quad\left(f, g \in H_{q}\right),} \\
\|f\|_{(\alpha)}:=\left([f, f]_{(q)}\right)^{1 / 2} \quad\left(f \in H_{q}\right), \\
H_{-q}:=\left\{T \in \mathscr{D}\left(\boldsymbol{R}^{n}\right)^{\prime} ; \exists O>0 \forall \varphi \in \mathscr{D}\left(\boldsymbol{R}^{n}\right):|\langle T, \varphi\rangle| \leqslant O\|\varphi\|_{(q)}\right\}, \\
\|T\|_{(-q)}:=\sup \left\{\langle T, \varphi\rangle \mid ; \varphi \in \mathscr{D}\left(\boldsymbol{R}^{n}\right),\|\varphi\|_{(q)} \leqslant 1\right\} \quad\left(T \in H_{-q}\right) .
\end{gathered}
$$

By means of the spaces $\left(H_{\alpha} ; q \in Z\right)$ we obtain a particularly useful representation of the space $\left(\mathscr{S}\left(\boldsymbol{R}^{n}\right)^{\prime}, \beta\left(\mathscr{S}^{\prime}, \mathscr{S}\right)\right)$.

(4.1) $\mathscr{S}\left(\boldsymbol{R}^{n}\right)^{\prime}=\bigcup_{q \in \mathbb{N}_{0}} H_{-q}$ and the LB-space topology defined by $\bigcup_{q \in N_{0}}\left(H_{-q},\|\cdot\|_{(-q)}\right)$ coincides with the strong topology $\beta\left(\mathscr{P}^{\prime}, \mathscr{P}\right)$.

By $\mathfrak{S}_{q}$ we denote the $\|\cdot\|_{(q)}$-topology on $H_{q}(q \in \mathbb{Z})$, the standard topology on $L_{\text {loo }}^{1}\left(\boldsymbol{R}^{n}\right)$ will be denoted by $\mathfrak{R}_{\text {loc }}^{1}$, and $\mathfrak{H}_{-\alpha} \vee \mathfrak{R}_{100}^{1}$ denotes the initial topology on $H_{-q} \cap L_{\text {loo }}^{1}\left(\boldsymbol{R}^{n}\right)$ with respect to the map

$$
H_{-q} \cap L_{100}^{1}\left(\boldsymbol{R}^{n}\right) \rightarrow\left(H_{-q}, \mathfrak{h}_{-q}\right) \times\left(L_{100}^{1}, \Re_{100}^{1}\right),
$$

$f \mapsto(f, f)\left(q \in \mathbf{N}_{0}\right)$.

Now we can define the above-mentioned topologies on $S_{r}\left(\boldsymbol{R}^{n}\right)$.

(4.2) Definimion. (a) By $\mathfrak{B}$ we denote the LF-space topology on $S_{\mathrm{r}}\left(\boldsymbol{R}^{n}\right)$, which is defined by

$$
\bigcup_{q \in N_{0}}\left(H_{-q} \cap L_{100}^{1}\left(\boldsymbol{R}^{n}\right), \mathfrak{H}_{-q} \vee \Re_{100}^{1}\right) .
$$

(b) By $\mathfrak{G}$ we denote the topology $\beta\left(\mathscr{S}^{\prime}, \mathscr{S}\right) \vee \Re_{100}^{1}$ on $S_{\mathrm{r}}\left(\boldsymbol{R}^{n}\right)$.

(4.3) Remarks. (a) We obviously have $₹ \supset(\mathfrak{5}$.

(b) The completeness of $\mathfrak{S}_{-q} \vee \Re_{100}^{1}\left(q \in \boldsymbol{N}_{0}\right)$ and of $\mathfrak{G}$ is proved as the completeness of the usual Sobolev spaces $W^{m, p}$. It can be shown that $\mathfrak{S}_{-q} \vee \Re_{100}^{1}$ is not normable for $q>n / 2+1$ (cf. [6], p. 35).

(c) According to Grothendieck's theorom ([15], p. 16, Thm. A) each two defining spectra for an LW'-space are equivalent. Therefore the definition of $\widetilde{F}$ does not depend on the special representation of $\beta\left(\mathscr{S}^{\prime}, \mathscr{S}\right)$.

(d) Since $\sigma\left(\mathscr{S}^{\prime}, \mathscr{S}\right)$ and $\sigma\left(L_{100}^{1}, L_{c}^{\infty}\right)$ are sequentially complete, we obtain that $\sigma\left(S_{\mathrm{r}},\left(S_{\mathrm{x}},(\mathfrak{W})^{\prime}\right)\right.$ is sequentially complete, too.

(e) If $q>n / 2$, we have $L^{1}\left(\boldsymbol{R}^{n}\right) \subset H_{-q}$ and the inclusion $\left(L^{1}\left(\boldsymbol{R}^{n}\right)\right.$, $\left.\|\cdot\|_{1}\right) C_{\rightarrow}\left(H_{-q},\|\cdot\|_{(-q)}\right)$ is continuous. This can be used to prove a result similar to $(3.4 \mathrm{~d})$ :

For every compact set $K \subset \boldsymbol{R}^{n},\left(L^{1}(K),\|\cdot\|_{1}\right)$ is a complemented subspace of $\left(H_{-q} \cap L_{\text {loc }}^{\mathrm{l}}\left(\boldsymbol{R}^{n}\right), \mathfrak{S}_{-q} \vee \Re_{\mathrm{loc}}^{1}\right)(q>n / 2),\left(\mathcal{S}_{\mathbf{r}}\left(\boldsymbol{R}^{n}\right), \mathfrak{F}\right)$, and of $\left(\mathcal{S}_{\mathbf{r}}\left(\boldsymbol{R}^{n}\right), \mathfrak{G}\right)$. (f) A routine calculation shows that the spaces $\left(H_{-\alpha},\|\cdot\|_{(-\alpha)}\right)\left(q \in \boldsymbol{N}_{0}\right)$ and $\left(I_{\text {loo }}^{1}\left(\boldsymbol{R}^{n}\right), \Re_{\text {loo }}^{l}\right)$ have the approximation property with respect to cutting and regularization (Schwartz [26], Ch. T, pp. 7, 8). This implies that the spacos $\left(S_{x}\left(\boldsymbol{R}^{n}\right)\right.$, \&) and $\left(S_{x}\left(\boldsymbol{R}^{n}\right),(\mathfrak{5})\right.$ both have the approximation property with respect to eutting and regrlarization.

The compactness of the inclusions $\left(H_{-q}, \mathfrak{H}_{-q}\right) C_{-}\left(H_{-q-1}, \mathfrak{H}_{-q-1}\right)\left(q \in \boldsymbol{N}_{0}\right)$ can now be used to obtain a rather complete description of the topologies F and (5. The crucial point is the completeness of $\tilde{F}$. For the proof of the completeness of \& we first show the somewhat tochnical fact that $₹$ and (5 coincide on rather large subsets of $S_{\boldsymbol{r}}\left(\boldsymbol{R}^{n}\right)$, although these topologies even have different duals.

(4.4) Truontom. (a) Let $B \in S_{\mathrm{r}}\left(\boldsymbol{R}^{n}\right)$ be $\beta\left(\mathscr{S}^{\prime}, \mathscr{S}\right)$-bounded. Then there exists $q \in \boldsymbol{N}_{0}$ swoh that $B \subset I_{-a} \cap L_{100}^{1}\left(\boldsymbol{R}^{n}\right)$ and is $\mathfrak{S}_{-q^{-}}$bounded. In particular, to every (5-bounded subset $\mathcal{B} \subset S_{\mathrm{x}}\left(\boldsymbol{R}^{n}\right)$ there exists $q \in \boldsymbol{N}_{0}$ such that $B \subset H_{-q} \cap L_{100}^{1}\left(\boldsymbol{R}^{n}\right)$ and is $\mathfrak{S}_{-\alpha} \vee \mathfrak{R}_{100}^{1}-$ bounded.

(b) Let $B \subset H_{-\alpha} \cap L_{100}^{1}\left(\boldsymbol{R}^{n}\right)$ be $\mathfrak{H}_{-q^{-}}$bounded. Then we have $\mathfrak{F} \cap B$ $=\left(\mathfrak{H}_{-\alpha-1-1} \vee \mathfrak{R}_{100}^{1}\right) \cap B=(\mathfrak{5} \cap B$. Morenver, also the corresponding weak topotogies induce the same topology on $B$.

(c) F has a zero-nbhd.-base consisting of $\mathfrak{5}$-closed sets. Thus $\&$ is complete and $\mathscr{F}=\beta\left(S_{\mathfrak{w}},\left(S_{r},(\mathfrak{b})^{\prime}\right)\right.$ holds.

(d) $\mathfrak{F}$ is the finest locally convex topotogy on $S_{x}\left(\boldsymbol{R}^{n}\right)$ which coincides on all (5-bounded subsets with $\mathfrak{5}$.

(e) $\left(S_{x}, \mathscr{F}\right)^{\prime}=\bigcap_{q \in N_{0}}\left(H_{q}+L_{c}^{\infty}\right) \supsetneqq \mathscr{S}\left(\boldsymbol{R}^{n}\right)+I_{c}^{\infty}=\left(S_{x}, \mathfrak{G}\right)^{\prime}$.

Proof. (a) Since $\left(\mathscr{S}\left(\boldsymbol{R}^{n}\right)^{\prime}, \beta\left(\mathscr{S}^{\prime}, \mathscr{P}\right)\right)=\bigcup_{q \in N_{0}}\left(H_{-\alpha},\|\cdot\|_{(-q)}\right)$ is a complete LB-space, the first part of the assertion follows from Köthe [20], p. 225, (5). If $B \subset S_{\mathrm{r}}\left(\boldsymbol{R}^{n}\right)$ is $\left(5-b o u n d e d\right.$, it is a priori $\mathfrak{R}_{\mathrm{loc}}^{1}$-bounded and thus $\mathfrak{H}_{-q}$ $\vee \Re_{100}^{1}$-bounded for some $q \in \boldsymbol{N}_{0}$.

(b) Let $B \subset H_{-\alpha} \cap L_{100}^{1}\left(\boldsymbol{R}^{n}\right)$ be $\mathfrak{H}_{-q^{-}}$bounded. Since the inclusion $\left(H_{-\alpha}, \mathfrak{S}_{-\alpha}\right) C_{\rightarrow}\left(H_{-q-1}, \mathfrak{h}_{-q-1}\right)$ is compact, the closure $D$ of $B$ in $\left(H_{-q-1}\right.$, $\left.\mathfrak{L}_{-\alpha-1}\right)$ is $\mathfrak{S}_{-q-1^{2}}$ compact. This implies

$$
\mathfrak{H}_{-q-1} \cap D=\beta\left(\mathscr{P}^{\prime}, \mathscr{P}\right) \cap D .
$$

By the transitivity of initial topologies we therefore have

$$
\left(\mathfrak{S}_{-\alpha-1} \vee \Re_{100}^{1}\right) \cap B=\left(\beta\left(\mathscr{S}^{\prime}, \mathscr{S}\right) \vee \mathfrak{R}_{\mathrm{loc}}^{1}\right) \cap B=\mathscr{b} \cap B .
$$

Now we use the obvious inclusions $\left(\mathfrak{S}_{-q-1} \vee \Re_{\mathrm{loc}}^{1}\right) \cap B \supset \mathfrak{F} \cap B \supset \mathfrak{G} \cap B$ to obtain the first part of the assertion. The result for the corresponding weak topologies is proved in the same way. 
(c) (This proof is due to $\mathrm{S}$. Dierolf.) Let $B_{q}:=\left\{f \in H_{-q} \cap L_{\mathrm{loo}}^{1} ;\|f\|_{(-q)}\right.$ $\leqslant q\}\left(q \in \boldsymbol{N}_{0}\right)$. Then

$$
\bigcup_{q \in \mathbb{N}} B_{q}=\mathscr{S}\left(\boldsymbol{R}^{n}\right)^{\prime} \cap L_{100}^{1}\left(\boldsymbol{R}^{n}\right)
$$

and $B_{l c}+B_{l} \subset B_{k+l}(k, l \in \mathbf{N})$ hold. Thus the sequence $\left(\boldsymbol{B}_{q} ; q \in \boldsymbol{N}\right)^{\prime \prime \prime s}$ satisfies the condition (C) of Roelcke [24], p. 58.

Let $\mathfrak{I}$ denote the finest locally convex topology on $\mathbb{S}_{r}\left(\boldsymbol{R}^{n}\right)$ which coincides on each set $B_{q}(q \in \boldsymbol{N})$ with (5. According to Lemma $1,(4)$ of Roelcke $[24]$, pp. $58,59, \Im$ has a zero-nbhd.-base consisting of (5)-closed sets. By (b) from above we have $\mathfrak{F} \cap B_{q}=\mathfrak{5} \cap B_{q}=\mathfrak{I} \cap B_{\alpha}(q \in N)$, i.e., $\widetilde{J}$ is also the finest locally convex topology on $S_{r}\left(\boldsymbol{R}^{n}\right)$, which on each set $B_{q}(q \in N)$ coincides with $\mathfrak{F}$. The barrelledness of the LF-space topology $\tilde{F}$ together with Corollary 1 of Roelcke [24], p. 68, yield $\mathfrak{F}=\Im$. The completeness of $\widetilde{F}$ now follows from the completeness of $\mathfrak{G}$ by Köthe $[20]$, p. $210,(4)$.

Since $\mathfrak{F}$ has a zero-nbhd.-base consisting of $(\mathfrak{5}$-closed sets and is barrelled, we obtain

$$
\mathfrak{F} \subset \beta\left(S_{\mathrm{r}},\left(S_{\mathrm{r}}, \mathfrak{G}\right)^{\prime}\right) \subset \beta\left(S_{\mathrm{r}},\left(S_{r}, \mathfrak{\mho}\right)^{\prime}\right)=\mathfrak{\mho}
$$

(Köthe $[20]$, p. 257, (1)) and thus $\mathfrak{F}=\beta_{\cdot}\left(S_{\mathrm{r}},\left(S_{\mathrm{r}}, \mathfrak{G}\right)^{\prime}\right)$.

(d) Let $\mathfrak{\Im}$ denote the finest locally convex topology on $S_{r}\left(\boldsymbol{R}^{n}\right)$ which on each (5-bounded subset coincides with $\left(5\right.$. Let the sequenco $\left(B_{q} ; q \in N\right)$ be defined as in (c). Let $B \subset S_{r}\left(\boldsymbol{R}^{n}\right)$ be (5-bounded. According to (a) thore exists $q \in \boldsymbol{N}$ such that $B \subset B_{q}$. Using the result $\mathfrak{F} \cap B_{q}=\mathfrak{G} \cap B_{q}$ from the proof of (c) we obtain $\mathfrak{F} \cap B=\mathfrak{S} \cap B$ and thus $\mathfrak{I} \supset \mathbb{F}$. Since $\mathfrak{F}$ is ultrabornological, we infer $\mathfrak{\&}=\mathfrak{I}$ (cf. [4], p. 125).

(e) By (4.3f) the space $\mathscr{D}\left(\boldsymbol{R}^{n}\right)$ is dense in each of the spaces $\left(H_{-q}\right.$ $\left.\cap L_{\text {loc }}^{1}, \mathfrak{H}_{-q} \vee \Re_{\mathrm{loc}}^{1}\right)\left(q \in \boldsymbol{N}_{0}\right),\left(\boldsymbol{S}_{\mathrm{r}}\left(\boldsymbol{R}^{n}\right), \mathfrak{F}\right)$, and $\left(\boldsymbol{S}_{\mathrm{r}}\left(\boldsymbol{R}^{n}\right),(\mathfrak{b})\right.$. Wo thus obtain

$\left(H_{-\alpha} \cap L_{100}^{1}, \mathfrak{S}_{-q} \vee \Re_{100}^{1}\right)^{\prime}=\left(H_{-\alpha}, \mathfrak{S}_{-\alpha}\right)^{\prime}+\left(L_{\mathrm{loc}}^{1}, \mathfrak{R}_{\mathrm{loc}}^{1}\right)^{\prime}=I_{\alpha}+I_{c}^{\infty} \quad\left(q \in \boldsymbol{N}_{0}\right)$,

$\left(\mathcal{S}_{\mathrm{r}}, \beta\left(\mathscr{S}^{\prime}, \mathscr{S}\right) \vee \mathfrak{R}_{\mathrm{loc}}^{1}\right)^{\prime}=\left(\mathscr{S}^{\prime}, \beta\left(\mathscr{S}^{\prime}, \mathscr{S}\right)\right)^{\prime}+\left(L_{\mathrm{lo0}}^{1}, \mathfrak{R}_{\mathrm{loc}}^{1}\right)^{\prime}=\mathscr{P}+L_{L_{0}}^{\infty}$,

$$
\begin{aligned}
& \left(S_{x}, \mathfrak{F}\right)^{\prime}=\left(\bigcap_{q \in N_{0}}\left(H_{-q} \cap L_{100}^{1}, \mathfrak{S}_{-q} \vee \Re_{\text {loc }}^{1}\right)\right)^{\prime}
\end{aligned}
$$

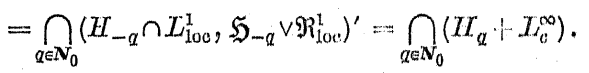

We first sketch a proof of the relation

for $n=1$.

$$
\bigcap_{q \in \mathbf{N}_{0}}\left(H_{q}+L_{c}^{\infty}\right) \supsetneqq \mathscr{P}\left(\boldsymbol{R}^{n}\right)+L_{c}^{\infty}
$$
that (i) $f_{t c}$ is $(7-1)$-times continuously differentiablo; $\partial^{x+1-1} f$ coincides in a neighbourhood of $7+1 / 2$ with a scalar multiple of the Dirac-measure concontrated at $z_{i}+1 / 2\left(\eta_{i} \in \boldsymbol{N}\right)$,

(ii) $\operatorname{supp}\left(f_{k}\right) \subset(\%, k+1)\left(k_{k} \in \boldsymbol{N}\right)$,

(iii) $\left\|f_{r_{c}}\right\|_{(k)} \leqslant 2^{-t_{c}}\left(\eta_{i} \in \boldsymbol{N}\right)$

hold. (To construct such a secquenco of functions ono multiplies suitalle iterated primitives of translations of tho Dirac-moasure by cut-off functions.) Then $f:=\sum_{k \in \mathbb{N}} f_{l_{0}}$ is continuous and wo have $f \cdot \chi_{[l, c)} \in H_{l_{k}}(\boldsymbol{R}), f \cdot \chi_{(-\infty, k)}$ $\in L_{0}^{\infty}(\boldsymbol{R})$ for all $l_{i} \in \boldsymbol{N}$. Thus $f \in \bigcap_{k \in \mathcal{N}}\left(I_{l o}+L_{0}^{\infty}\right)$. Now suppose $f \in \mathscr{S}(\boldsymbol{R})+L_{c}^{\infty}$. Then there is a compact set $K \subset \boldsymbol{R}$ and a set $N \subset \boldsymbol{R}$ of measure zero such that a suitable alteration of $f$ on $N$ is infinitely differentiablo outside $K$. Since $f$ is continuous, the regularity of $f$ cannot be improved by a change of the values of $f$ on sets of measure zero. By construction wo have $f \notin \mathscr{E}(\boldsymbol{R} \backslash K)$ for every compact set $K \subset \mathbb{R}$. This contradiction shows $f \notin \mathscr{S}(\boldsymbol{R})+L_{c}^{\infty}$.

To prove the result for $n>1$ we consider instead of $f$ the function $\tilde{f}\left(x_{1}, \ldots, x_{n}\right):=f\left(x_{1}\right) \cdot \psi\left(x_{2}, \ldots, x_{n}\right)\left(x \in \boldsymbol{R}^{n}\right)$, whero $p \in \mathscr{D}\left(\boldsymbol{R}^{n-1}\right)$ is equal to 1 on the set $\left\{\left(x_{2}, \ldots, x_{n}\right) \in \boldsymbol{R}^{n-1} ; x_{2}^{2}+\ldots+x_{n}^{2} \leqslant 1\right\}$.

The observations (3.5) also apply to the space $\left(S_{\mathrm{r}}\left(\boldsymbol{R}^{n}\right)\right.$, F $)$. Wo finally romark that the sets $B_{\alpha}(q \in \boldsymbol{N})$ from the proof of (4.4.c) are not (5-bounded (cf. [6], p. 43).

5. Application of the constructions to the space $\mathscr{\mathscr { H }}(\Omega)$. In this section wo shall describe some interesting phenomenons which occur if wo tako $\mathscr{B}(\Omega)$ as a space of testifunctions.

(5.1) Let $\Omega=\stackrel{\Omega}{\Omega} \subset \boldsymbol{R}^{n}$. Wo put

$$
\stackrel{\circ}{\mathscr{B}}(\Omega):=\left\{p \in \mathscr{E}(\Omega) ; \partial^{\alpha} p \in C_{0}(\Omega)\left(\alpha \in \mathbf{N}_{0}^{n}\right)\right\} .
$$

This space is provided with the Fréchet-spaco topology $\mathfrak{I}_{0}^{\infty}$ which is generated by the norms

$$
p_{m}(p):=\max \left\{\left\|\partial^{a} \varphi\right\|_{\infty} ;|\alpha| \leqslant m\right\}
$$

$\left(\varphi \in \mathscr{\mathscr { B }}(\Omega), m \in \boldsymbol{N}_{0}\right) . A$ detailed investigation of this spaco was given in [7] and in Dierolf, Voigt [9].

(5.2) Wo first consider the case $\Omega=\boldsymbol{R}^{n}$. The approximate unit $\left(\eta_{k} ; \eta_{i} \in \boldsymbol{N}\right)$ constructed in the proof of $(1.1)$ is $\mathfrak{T}_{0}^{\infty}$-bounded. With a proof analogous to that of (1.1) we obtain

$$
\left\{f \in L_{100}^{1}\left(\boldsymbol{R}^{n}\right) ; f \cdot p \in L^{1}\left(\boldsymbol{R}^{n}\right) \forall p \in \mathscr{\mathscr { B }}\left(\boldsymbol{R}^{n}\right)\right\}=I^{1}\left(\boldsymbol{R}^{n}\right),
$$

i.e., the space $\stackrel{\circ}{\mathcal{B}}_{\text {ar }}\left(\boldsymbol{R}^{n}\right)$ of the absolutely regular elements of $\stackrel{\circ}{\mathscr{B}}\left(\boldsymbol{R}^{n}\right)^{\prime}$ is just $L^{1}\left(\boldsymbol{R}^{n}\right)$. The topologies on $\stackrel{\circ}{B}_{\text {ar }}\left(\boldsymbol{R}^{n}\right)$ constructed as in (3.1b) and (3.1c) 
evidently coincide with the $\|\cdot\|_{1}$-topology. However, an analogue to the result (3.2a) is obviously not valid. Moreover, the topology $\mathfrak{T}_{2}^{\prime}$ on $\stackrel{\circ}{B}_{\text {ar }}\left(\boldsymbol{R}^{n}\right)$

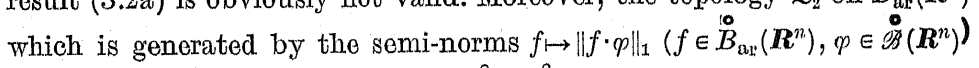
is not finer than the topology $\sigma\left(\stackrel{\circ}{B}_{a r}, \stackrel{\circ}{B}_{a r}^{\prime}\right)=\sigma\left(L^{1}, L^{\infty}\right)$. To prove this statement, one considers a sequence formed of translatos of a fixed function $\psi \in \mathscr{D}\left(\boldsymbol{R}^{n}\right)$.

The theory of the space $\stackrel{\circ}{B}_{r}\left(\boldsymbol{R}^{n}\right)$ of regular elements in $\mathscr{\mathscr { B }}\left(\boldsymbol{R}^{n}\right)^{\prime}$ is not

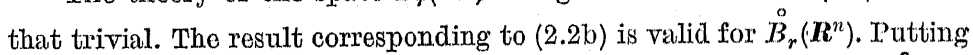
$g(x):=\left(1+x^{2}\right)^{-1} \exp \left(i \cdot e^{x}\right)(x \in \boldsymbol{R})$ we obtain $g \in L^{1}(\boldsymbol{R}) \cap \mathscr{E}(\boldsymbol{R}), \partial^{k} g \in \stackrel{\circ}{B}_{r}(\boldsymbol{R})$ $\left(l_{i} \in \boldsymbol{N}\right)$, and $\partial g \in \stackrel{\circ}{B}_{r}(\boldsymbol{R}) \backslash L^{1}(\boldsymbol{R})$.

(5.3) Now we consider the case $\Omega \neq \boldsymbol{R}^{n}$. Obviously there does not exist a sequence $\left(\eta_{k} ; k \in \mathbf{N}\right)$ in $\mathscr{D}(\Omega)$ which satisfies (AP. 1) and (AP. 2). (Cf. $[5]$, p. 198, 3. for an interpretation of this fact.) To determine the absolutely regular elements of $\mathscr{\mathscr { B }}(\Omega)^{\prime}$ we therefore cannot argue as in the proof of (1.1). In fact, for $\Omega:=(0,1) \subset \boldsymbol{R}$ the example $\hat{x}^{-1} \in \stackrel{\circ}{\mathcal{B}}_{\mathrm{ar}}(\Omega) \backslash L^{1}(\Omega)$ shows that for $\Omega \neq \boldsymbol{R}^{n}$ the space $\stackrel{\circ}{B}_{\text {ar }}(\Omega)$ may be strictly larger than $L^{1}(\Omega)$. With the help of the boundary behaviour of the functions $p \in \mathscr{\mathscr { B }}(\Omega)$ and. of the regularized boundary distance (Stein [28], p. 171) it is proved in $[6]$, p. 85 ff., that

$$
\begin{aligned}
& \stackrel{\circ}{B}_{\text {ar }}(\Omega)=\left\{f \in L_{\text {loc }}^{1}(\Omega) ; f \cdot \varphi \in L^{1}(\Omega) \forall p \in \stackrel{\circ}{\mathscr{B}}(\Omega)\right\}=\bigcup_{m \in \mathbb{N}} L^{1}\left(\Omega, \varrho^{m}\right) \\
& =\left\{f \in L_{\mathrm{loc}}^{1}(\Omega) ; f \cdot \psi \in L^{1}(\Omega) \forall \psi \in \stackrel{\circ}{\mathscr{B}}(\Omega)^{\prime \prime}\right\}
\end{aligned}
$$

holds, where $\varrho(x):=\min \{1, \operatorname{dist}(x, \mathrm{C} \Omega)\} \quad(x \in \Omega)$, and the bidual $\mathscr{\mathscr { H }}(\Omega)^{\prime \prime}$ of $\left(\mathscr{\mathscr { B }}(\Omega), \mathfrak{T}_{0}^{\infty}\right)$ is determined in [9], p. 76, Thm. (4.8). Thus the natural topology on $\stackrel{\circ}{B}_{\mathrm{ar}}(\Omega)$ is a proper LB-space topology and we could proceed similarly as in Section 3. However, an argument similar to that given in (5.2) shows that the topology on $\stackrel{\circ}{B}_{\text {ar }}(\Omega)$ generated by the semi-norms $f \mapsto\|f \cdot \varphi\|_{1}\left(f \in \stackrel{\circ}{\mathrm{Bar}}_{\mathrm{ar}}(\Omega), \varphi \in \mathscr{B}(\Omega)\right)$ is strictly coarser than tho natural topology on $\stackrel{\circ}{B}_{\text {arr }}(\Omega)$, unless $\Omega$ is quasi-bounded (i.e., $\{x \in \Omega$; dist $(x, \mathrm{C} \Omega) \geqslant \varepsilon\}$ is compact for all $\varepsilon>0$ ). On the other hand, it can be shown that to every $\mathfrak{T}_{0}^{\infty}$-bounded subset $B$ of $\mathscr{\mathscr { B }}(\Omega)$ there exists $\psi \in \mathscr{\mathscr { B }}(\Omega)^{\prime \prime}$ such that $|p(x)|$ $\leqslant \psi(x) \quad(x \in \Omega)$ holds for all $\varphi \in B$. Therefore the family of semi-norms $f \mapsto\|f \cdot \psi\|_{1}\left(f \in \dot{B}_{\text {ar }}^{\circ}(\Omega), \psi \in \mathscr{\mathscr { H }}(\Omega)^{\prime \prime}\right)$ does generate the natural topology on $\stackrel{\circ}{B}_{\mathrm{ar}}(\Omega)$.
As far as $\dot{B}_{x}(\Omega)$ is concerned we only remark that a representation of $\stackrel{\circ}{\mathscr{B}}(\Omega)^{\prime}$ as an inductive limit of a sequence of Hilbert-spaces, as used in Section 4, cannot exist if $\Omega$ is not quasi-bounded. According to Komatsu [21], p. 372, Thm. 6, such a limit is always reflexive, and $\left(\mathscr{\mathscr { O }}^{\circ}(\Omega)^{\prime}, \beta\left(\mathscr{\mathscr { B }}^{\prime}, \mathscr{\mathscr { B }}\right)\right)$ is reflexive if and only if $\Omega$ is quasi-bounded (cf. [9], p. 78, Thm. (4.11), and Köthe [20], p. 396, (5)).

\section{References}

[1] P. Antosik, J. Mikusinski, R. Sikorski, Thory of distributions. The sequential approach, PWN-Polish Sciontific Publishers, Warszawa 1973.

[2] K.-D. Bierstedt, R. Meiso, Bemerloungen übor die Approximationseigensehaft lokallconvexer Funitctionenräume, Math. Ann. 209 (1974), 99-107.

[3] C. Chevalley, Theory of distributions, Lectures at Columbia University, 1950-51.

[4] P. Dierolf, Summierbare Familien und assiziierte Orlicz-Pettis-Topologien, Dissertation, Universität München, 1976.

[5] - L'espace $\stackrel{\circ}{\mathscr{B}}(\Omega)$ et les distributions sommables, C. R. Acad. Sci. Paris 288 (1979), 197-199.

[6] - Zwei Räume regulärer temperierter Distributionen, Habilitationsschrift, Universität München, 1978

[7] P. Dierolf, S. Dierolf, Topological properties of the dual pair $\left\langle\stackrel{\circ}{\mathscr{B}}(\Omega)^{\prime}, \stackrel{\circ}{\mathscr{B}}(\Omega)^{\prime \prime}\right\rangle$, Pacific J. Math. 108 (1983), 51-82.

[8] P. Dierolf, J. Voigt, Oonvolution and S'-convolution of distributions, Collect. Math. 29 (1978), 185-196.

[9] -, - Caloulation of the bidual for some function spaces. Integrable distributions, Math. Ann. 253 (1980), 63-87.

[10] J. Dieudonné, Sur les espaces de Köthe, J. Analyse Math. 1 (1951), 81-115.

[11] L. E. Fraonkel, Formulae for high derivatives of composite funotions, Math. Proc. Cambridge Philos. Soc. 83 (1978), 159-165.

[12] D. J. H. Garling, A generalized form of inductive-limit topology for vector spaces, Proc. London Math. Soc. 14 (1964), 1-28.

[13] I. M. Gel'fand, G. E. Shilov, Generalized functions, vol. 2, Academic Press, Now York 1968.

[14] A. Grothendieck, Sur les applications linéaires faiblement compactes d'espases du type $O(K)$, Canad. J. Matil. 5 (1953), 129-173.

[15] - Produits tensoriels topologiques et espaces nucléaires, Mem. Amer. Math. Soc. 16 (1966).

[10] E. Hewitt, K. Stromberg, Real and abstract analysis, Springer-Verlag, Berlin 1969.

[17] L. Hörmander, On the division of distributions by polynomials, Ark. Mat. 3, 53 (1.958), 555-568.

[18] - Linear partial differential operators, Springer-Vorlag, Berlin 1964.

[19] J. Horváth, Topological veotor spaces and distributions, vol. I, Addison-Wesley Publishing Comp., Reading, Mass. 1966.

[20] G. Köthe, Topological vector spaces, vol. I, Springer-Verlag, Berlin 1969.

[21] H. Komatsu, Projective and injective limits of wealcly compact sequences of locally convex spaces, J. Math. Soc. Japan 19 (1967), 366-383. 

[22] Y. Kömura, On linear spaces of functions, T. of the facultiy of sciones, Univ.
of Tokyo 9 (1901-1963), 203-248.

[23] J. Kučora, Fourier $I_{2}$-transforms of distributions, Czechoslovalk Matil. J. I9 (1969), 143-153.

[24] W. Rooleke, On the finest locally conves topology agreeing with a given topology on a sequence of absolutcly convex sets, Math. Ann. 198 (1972), 57 80 .

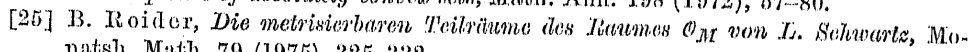
natsh. Matih. 79 (1975), 325-332.

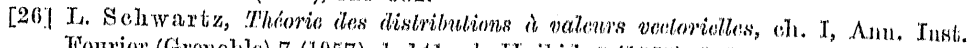
Fourior (Gronoble) 7 (1.957), 1-141: ch. Th, ilial. 8 (1958), 1-209.

[27] - Théoric des distributiont, Horman, Taris 1966.

[28] E. M. Stoin, Singular integrals and difforentiability proporlion of funations, Prin. coton Univarsity Pross, Princeton, N. J. 1970.

[29] Z. Szmy dt, On regular temperate distributions, studia Malih. 44: (1072), 309).314.

[30] - TFourier transformation and linewr differential equations, D. Roids] Publising Coinpany, Dordrecht 1977.

[31] W. S. Wladimirow, Gleichungen der mathemalisehen Thysik, VdiB Dentacher: Verlag der Wissenschaften, Berlin 1072.

FB IV-MATHEMATIK DER UNIVERSTMÄT TRLHR

Postfach 3825, 5500 Trier, IRD 